Portland State University

PDXScholar

3-8-2019

\title{
From Refugee to Citizen: Rhizomes and Roots in the Digital Age
}

Julia Nett

Portland State University

Follow this and additional works at: https://pdxscholar.library.pdx.edu/honorstheses Let us know how access to this document benefits you.

\section{Recommended Citation}

Nett, Julia, "From Refugee to Citizen: Rhizomes and Roots in the Digital Age" (2019). University Honors Theses. Paper 667.

https://doi.org/10.15760/honors.680

This Thesis is brought to you for free and open access. It has been accepted for inclusion in University Honors Theses by an authorized administrator of PDXScholar. Please contact us if we can make this document more accessible: pdxscholar@pdx.edu. 
From Refugee to Citizen: Rhizomes and Roots in the Digital Age

by

Julia Nett

An undergraduate honors thesis submitted in partial fulfillment of the requirements for the degree of

Bachelor of Arts

in

University Honors

and

Anthropology

Thesis Adviser

Michele Gamburd, Ph.D.

Portland State University

2019

Contact: julia.v.nett@gmail.com 


\section{Acknowledgments}

Many, many thanks to my advisor, Dr. Michele Gamburd. Your advice, guidance, and mentorship mean the world to me. This thesis has always been more than just a paper, and it would not be what it is were it not for you. I am so grateful for your direction; you have taught me so much. An additional thank you to Dr. Alex Sager for spending so much time sharing ideas and discussing with me. You are both wonderful mentors. I would also like to thank BB, PC, and every single informant. Thank you for confiding in me and sharing your stories. It has been an honor writing this thesis for you. 


\section{Table of Contents}

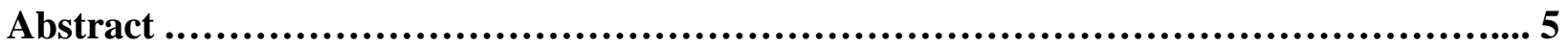

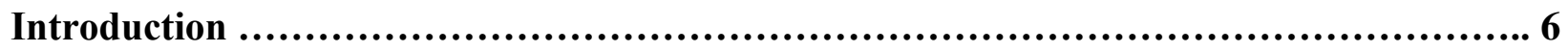

Literature Review ............................................................. 9

Digital Technologies and Resettlement .................................... 16

Methods ............................................................. 17

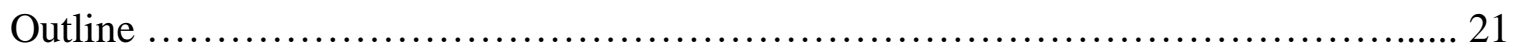

Chapter I. Hyphenated-American ..................................................... 24

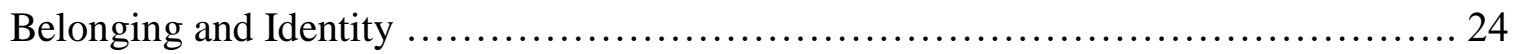

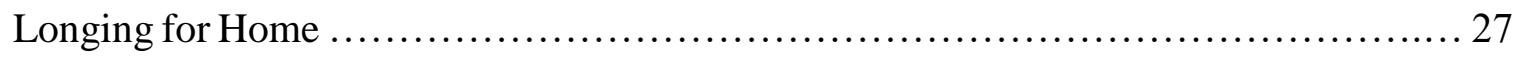

Rhizomes, Roots, and Belonging_ "We still look in the rearview mirror." ........... 31

People, not places .................................................. 37

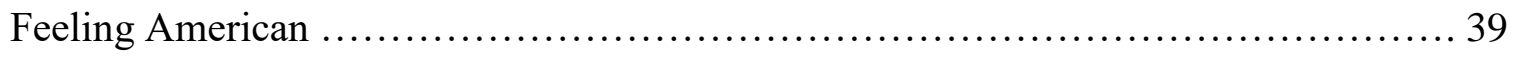

A Better Life: "We live for our family, not only for us." ....................... 39

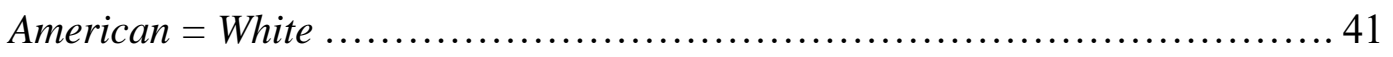

Legal Membership ................................................. 45

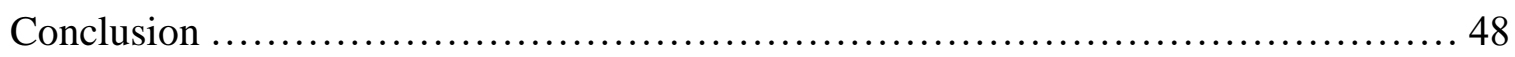

Chapter II. Online Resources: Social Media and the RCO ................................. 50

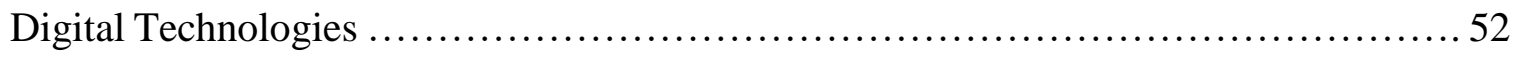

Facebook ............................................................ 53

Social Media as a Place for Hybrid Self-Identification ...................... 53

On "Being Real” And Reaffirmation Through Social Media .................... 59

On Comfort and Social Media as a "Friend" ................................ 63 


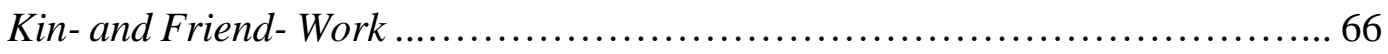

The RCO: Cultural Orientation Online ....................................... 71



The RCO as Non-Rhizomatic.............................................. 78

The RCO as a Place to The RCO as a Place to Consider “Being American”. .. 82

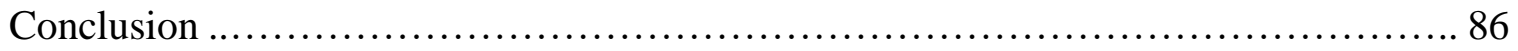

Chapter III. Becoming American Online ..................................................... 88

Facebook ............................................................ 88

The RCO as a Cultural Resource Center ....................................... 93

Reflections on the RCO — “Are We Going to...Build Something Mutual?” ............. 102

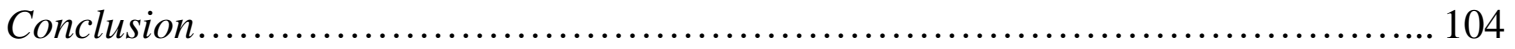

Conclusion........................................................................... 106

Doing Digital Ethnography ............................................. 107

Future Exploration.................................................... 109

Bibliography......................................................................... 112 


\begin{abstract}
This thesis examines digital media as platforms for current and former refugees to reaffirm and create themselves and to learn to be American. To think of refugees as "uprooted" with "roots that threaten to wither" (Malkki 1992, 32) is misguided. This thesis utilizes Deleuze and Guattari's idea of the rhizome (1987) to rethink current and former refugee experiences postresettlement in the US. With the rising ubiquity of digital media and digital technologies, increasing numbers of refugees resettle with smartphones and other technologies. These technologies provide current and former refugees opportunities to maintain hybridized selfconceptions and to feel they are both "here" and "there."

Based on 22 interviews with current and former refugees, 1 interview with an RCO employee, and participant observation, this thesis asks: How do refugees use Facebook and the RCO to learn about becoming American citizens? What is the RCO presenting? How do resettled refugees use social media to create and maintain their identity through interactions with friends and family, both locally and abroad? This investigation finds that although Facebook allows people to reaffirm themselves and their hybridity, the RCO focuses on "transplanting" one's roots from "there" to "here." As a result, this study contributes to a growing body of digital ethnographic literature, indicating that investigating what happens in the "virtual" sheds light onto refugee resettlement experiences in general.
\end{abstract}




\section{$\underline{\text { Introduction }}$}

We are in the midst of a supposed global refugee crisis in which people are reportedly fleeing their countries at higher rates than ever before. There are daily reports of refugees swarming Europe by boat, flooding the US-Mexico border, or arriving in "droves" to refugee camps (for disputation on the ethics of “crises" see Sager 2018). This heightened visibility of “the refugee" as an "anonymous corporeality" (Malkki 1996, 388) already “'fully labelled' in people's minds" (Zetter 1991, 40) indubitably calls for increased anthropological, ground-up exploration of the nuances and pluralities of refugees' social realities and lived experiences.

The Geneva Convention of 1951 defines a refugee as a person who, "owing to wellfounded fear of being persecuted for reasons of race, religion, nationality, membership of a particular social group or political opinion, is outside the country of his nationality and is unable or, owing to such fear, is unwilling to avail himself of the protection of that country; or who, not having a nationality and being outside the country of his former habitual residence as a result of such events, is unable or, owing to such fear, is unwilling to return to it" (UNHCR 1951). According to a June 2018 publication from the UNHCR, there are currently 68.5 million forcibly displaced people worldwide, 25.4 million of whom are refugees and 3.1 million asylum seekers (2018). Of these 25.4 million refugees, 102,800 have been resettled globally in the 2017 fiscal year. The United States admitted fewer than 54,000-1,340 of whom were resettled in Oregon (Oregon Department of Human Services 2018). The admissions cap was further limited to 45,000 for the 2018 fiscal year. Evidently, only a small fraction of refugees worldwide-less than one percent — is resettled and an even smaller fraction makes it to Oregon. For those few who are resettled, the journey is long and complicated, nor does it end upon arriving to the country of resettlement; refugees must navigate a new culture with all of its norms, rules, and 
expectations, while balancing bonds with their countr(ies) and culture(s) of origin.

Reformulation of self-identification and self-understanding. (Brubacker and Cooper 2000, 17-19) inevitably result.

A growing number of refugees arrive at their final resettlement location equipped with free messaging/social media accounts for quick and instantaneous communication with kin and friends abroad. For instance, a friend — whom I call Amir — was an interpreter for the US army in Afghanistan prior to resettling in Portland. He has mentioned that the Facebook messenger app has been helpful both pre- and post-arrival in Portland; before arriving, he spoke with American soldier friends and resettled kin and was familiar with what to expect of life here. Now that he is in Portland, he speaks with friends and family in Afghanistan almost daily through Facebook messenger. He expresses that Facebook has been key in helping him navigate American culture, while preserving ties with his social network abroad.

This thesis examines the construction of refugee citizenship and belonging in digital resources, namely the Refugee Center Online (RCO) and Facebook. The Refugee Center Online is the only fully online non-profit of its kind, dedicated to helping refugees learn to become "American" both legally and socially, with free citizenship classes, articles about American culture, and pieces on understanding American education, navigating resettlement, finding employment, and more. Facebook, on the other hand, is a way to reaffirm one's identity and reconnect with one's networks, both in the United States and elsewhere. So, while the RCO focuses more on learning to belong in America, Facebook is more about "being oneself" as a whole. In my research, I have asked: How do refugees use Facebook and the RCO to learn about becoming American citizens? What is the RCO presenting? What are refugees actually doing? 
How do resettled refugees use social media to create and maintain their identity through interactions with friends and family, both locally and abroad?

I will not delve too deeply into the machinations of the US refugee resettlement system here, although I present some preliminary context. A person can obtain US refugee status in one of three ways: one is referred to the refugee resettlement program by the UN High Commissioner on Refugees; one is a person of "special humanitarian concern" (US Citizenship and Immigration Services 2018) to the US resettlement program, such as Special Immigrant Visa (SIV) holders - Iraqis and Afghanis given a special visa and path to citizenship as recompense for their service with the United States Army; or, one can obtain refugee status in order to reunite with previously resettled members of family (called family reunification cases). The vetting process is rigorous and time-consuming. Once someone is cleared to enter the United States, the State Department refers their case to one of nine NGOs who relocates the refugee to a city and provides them with a case manager in a resettlement agency. The resettlement agency and local partners help the newcomer learn English, find a job, and "integrate." After one year, the newcomer can apply for permanent residency, at which point the person is no longer legally a refugee. Five years after arriving to the United States, refugees can apply for citizenship.

We cannot neglect to place refugee resettlement within its political climate. While often assumed that refugees flee and break cleanly from their cultures of origin, then are warmly welcomed to a host nation, this is not always the case. The political tensions surrounding refugees and the culture shock and trauma of resettlement frequently means refugees remain both "here" and "there" and, as a consequence, neither truly "here" nor "there" (Boehm 2012). Indeed, refugees are highly politicized in the United States; as outlined in his executive orders, President Trump reduced the number of admissible refugees for the 2017 fiscal year to 50,000 
nationwide (White House 2017a). He has further capped refugee admissions at 45,000 for the 2018 fiscal year (Bureau of Population, Refugees, and Migration 2017), and 30,000 for the 2019 fiscal year (Bureau of Population, Refugees, and Migration 2018). These caps, along with the executive orders calling for the suspension of refugee entry for 120 days and barring entry from five predominately Muslim countries (White House 2017a), are widely perceived as the President enforcing an explicit anti-refugee stance (see dissent by Justices Sotomayor and Ginsburg 2018 in Supreme Court ruling). This perceived anti-refugee position is bolstered by the recent June 2018 Supreme Court upholding of Trump's revised Travel Ban barring entry from 7 countries, 5 among them Muslim-majority countries (see Liptak and Shear 2018; Supreme Court ruling 2018; White House 2017b). Of course, such an unwelcoming attitude will have important implications for both newly arrived and already resettled refugees' sense of belonging. Unsurprisingly, it proves salient to critically examine the discourses surrounding belonging and citizenship and the ways in which refugees internalize them to become "American" both legally and socially_echoing Boehm's idea of the "social citizen” (Boehm 2012).

\section{Literature Review}

Following Deleuze and Guattari (1987), this thesis explores discourses and experiences surrounding resettlement that are both "rhizomatic" (the nuances of being both "here" and "there") and "rooted"/ "uprooted" (the sharp break between "here" and "there"). A break from "arborescent culture," the rhizome is "very different from the tree or root, which plots a point, fixes an order" (Deleuze and Guattari 1987, 7). A rhizome has "neither beginning nor end, but always a middle (milieu) from which it grows and which it overspills" (Deleuze and Guattari 1987, 21). It "may be broken, shattered at a given spot, but it will start up again on one of its old 
lines, or on new lines" (Deleuze and Guattari 1987, 9). Deleuze and Guattari note, "The tree imposes the verb 'to be,' but the fabric of the rhizome is the conjunction, 'and...and...and....' This conjunction carries enough force to shake and uproot the verb 'to be....' Therefore, the idea of uprooting oneself and starting over suggests "a false conception of voyage and movement (a conception that is methodical, pedagogical, initiatory, symbolic...)." The authors thus prefer the rhizome as an alternative to understanding movement because it "proceeds[] from the middle, through the middle, coming and going rather than starting and finishing (Deleuze and Guattari 1987, 25, emphasis added). This notion of the rhizome has informed my work in exploring how (current and former) refugees self-identify as both "here" and "there."

To think of refugees as "uprooted" is perhaps naïve and brings to mind Malkki's discussion of the "national order of things" as equaling the "natural order" (1992; 1995). She notes that "Motherland and fatherland, aside from their other historical connotations, suggest that each nation is a grand genealogical tree, rooted in the soil that nourishes it. By implication, it is impossible to be a part of more than one tree. Such a tree evokes both temporal continuity of essence and territorial rootedness" $(1992,28)$. Yet, the rhizome, as middle without a beginning or end, pushes back on this notion of rootedness, and highlights refugees' "coming and going" between "here" and "there." Hebdige's quote is particularly enlightening:

Rather than tracing back the roots . . to their source, I've tried to show how the roots themselves are in a state of constant flux and change. The roots don't stay in one place. They change shape. They change colour. And they grow. There is no such thing as a pure point of origin . . . but that doesn't mean there isn't history $(1987,10)$.

Using this idea, my thesis explores questions surrounding rhizomatic discourse and understandings. I ask, do refugees use Facebook or other social media in a rhizomatic way to maintain ties with old friends while also meeting new ones here? I additionally address issues 
such as how the RCO constructs American culture for refugee internalization and discuss its nonrhizomatic discourse.

Renowned scholars such as Malkki (1992, 1995), Agamben (1998), and Arendt (1951) have explored the nature of what it means to be a refugee. Arendt writes, "Something much more fundamental than freedom and justice, which are rights of citizens, is at stake when belonging to the community into which one is born is no longer a matter of course and not belonging no longer a matter of choice, or when one is placed in a situation where, unless he commits a crime, his treatment by others does not depend on what he does or does not do" $(1951,296)$. A person loses their "right to have rights" (Arendt 1951, 296) by default of being a refugee, which, according to Agamben is a human who only holds "bare," "creaturely" life $(1998,75)$ — the right to a strictly biological life-with little else because s/he lacks citizenship. A refugee arguably occupies a liminal space between being a citizen and existing as a floating, stateless being without the "right to have rights."

In her work, Malkki has questioned anthropology’s agenda toward refugees. She argues there is no singular "refugee experience," although anthropologists and many others have succumbed to this line of thinking. She notes that refugees are often stifled, become an “anonymous corporeality” (Malkki 1996, 388), and a "mere, bare, naked, or minimal humanity is set up" (Malkki 1996, 390). As such, “An obvious problem with the intellectual project of defining 'the refugee experience' is that it posits a single, essential, transhistorical refugee condition" (Malkki 1995, 11), disregarding the retention and reformulation of culture, identity, history, self-understanding, and "groupness" (Brubacker and Cooper 2000, 19) across time and space. 
Another problem with exploring refugee experiences is the legal definition itself. The Geneva definition of a refugee excludes large numbers of people worldwide who are nonetheless fleeing something as dangerous to one's well-being as persecution. That is, one person's plight is legally considered more legitimate for resettlement and admission into a country than another's who does not fit certain criteria. In particular, this definition excludes people who are not fleeing persecution, but who are fleeing extreme poverty, civil war, natural disasters, or climate change. The conventional definition of a refugee further excludes the large numbers of internally displaced people — estimated to be about 40 million globally in June 2018 (UNHCR 2018). Undeniably, this has important implications about whom a country is morally and legally obliged to take in (see Carens 2013; Miller 2005, for instance).

Because of its narrow scope and the limited resettlement obligations it allows nations to adopt, many scholars and organizations have moved toward challenging the "conventional" definition. Andrew Shacknove, for instance, notes that refugees should be defined as "persons whose basic needs are unprotected by their country of origin, who have no remaining recourse other than to seek international restitution of their needs, and who are so situated that international assistance is possible" $(1985,277)$. The Organization for African Unity defines a refugee as a someone who, "owing to external aggression, occupation, foreign domination or events seriously disturbing public order in either part or the whole of his country of origin or nationality, is compelled to leave his place of habitual residence in order to seek refuge in another place outside his country of origin or nationality" (UNHCR 1974, 3). These alternative definitions focus on a general lack of basic necessities and broader consequences of imperialism and capitalism. They acknowledge the "severe conceptual difficulties in establishing a normative meaning to a label which is as malleable and dynamic as refugee. [This label of the refugee] is 
contingent upon notions of persecution, and sovereignty... about which there is little consensus" (Zetter 1991, 40). In sum, these definitions extend "legitimate" claims for seeking refuge and asylum.

These definitions also highlight the conventional definition's Eurocentricity: the Geneva Convention, written in 1951, was created in Europe's post World War II context and was designated for displaced people in this very particular situation. Indeed, "Although its mandate requires UNHCR to seek 'permanent' solutions to the predicament of the refugee, it was established during the onset of the Cold War, at a time when most refugees were eastern Europeans escaping 'communism' and viewed as votes for liberal democracy. This perception facilitated their settlement in the West" (Harrell-Bond and Voutira 1992, 7; see also Lim 2013). In contrast, the Organization for African Unity's definition, for instance, is for a very different context - one of post-colonialism and neoliberalism, in which economically disadvantaged countries continue to contend with deep global and structural inequalities. Indeed, Saskia Sassen highlights that the "extractive logic" of "advanced capitalism" has significantly affected the refugee situations in the world today. These "emergent flows" highlight "longer histories of oppression and exploitation of a country's population and the destruction of local economies" (Sassen 2016, 223). Similarly, Wise writes that "Mechanisms of unequal development produce structural conditions, such as unemployment and inequality, which catapult the massive migration of dispossessed and marginalized people... Labor oversupply and worsening living conditions turn migration, particularly from peripheral countries, into a form of forced displacement" (2013, emphasis in original). In its Eurocentricity, the conventional refugee definition excludes so-called economic or climate migrants that emerge from pervasive historical and political processes. 
These alternative, broadened definitions recognize many more people as refugees to receive special consideration. The current constricted legal definition results in an epistemic act that forms knowledge about who is considered a "real" refugee and thus deserving of help. This definition is rigid and detached from people's lived reality, which is precisely what the broadened definitions counter by rendering the category of "refugee" more flexible and attuned to historical inequalities and oppression. As such, these alternative definitions highlight that the conventional definition was created, and is upheld, by detached privileged actors. These do not consult those potentially characterized as refugees, so as to avoid an influx of claims to "economic" or "climate" refugee status. The broadened characterizations, then, are significant advances toward including people's lived experiences, and the historical circumstances that shaped them, in the epistemic act of defining refugees.

All of this serves to highlight that the legal term "refugee" is incomplete and quite nebulous - persons fleeing climate change, civil war, dire economic woes, etc... flee just like conventional refugees. I could have chosen to study "economic refugees," or "climate change refugees," and their experiences would have been just as credible and important to study and understand as "conventional" refugees' experiences. Here, then, we find "two competing visions of the refugee — the deserving and assimilable immigrant who should be ... admitted into the country, and the racially undesirable and inassimilable immigrant who should be excluded from the country altogether" (Lim 2013, 1068). It is clear that refugees do not make up an easily demarcated, bounded, and homogenous group or identity. Indeed, Malkki notes that refugees are all too often essentialized in this way:

The quest for the refugee experience (whether as analytical model, normative standard, or diagnostic tool) reflects a wider tendency, in many disciplines, to seize upon political or historical processes and then to inscribe aspects of those processes in the bodies and 
psyches of the people who are undergoing them. In this way, very mobile, unstable social phenomena may be imagined as essential "traits" and "characteristics" attached to, or emanating from, individual persons. Instead of being content with seeing commonalities and differences in the socio-historical processes that produce refugees ... researchers tend to seek to fix and make permanent something "essential" about these processes and to do so by personalizing them. Almost like an essentialized anthropological "tribe," refugees thus become not just a mixed category of people sharing a certain legal status; they become "a culture," "an identity"..."a social world“(1995, 511).

Furthermore, refugees do not remain refugees forever. Yet, when we think of refugees, the term envelops a person and puts their trauma and supposed lack of options at the forefront of their identity; often, we label a person as a perpetual refugee and seldom move toward a more holistic conception of the person. Having stated this, my reason for studying "conventional" refugees has more to do with convenience and ease of access than with a desire to study a "bounded" cultural group. My interest was in exploring how people who had to flee their countries of origin understand and experience life here, how they have changed, how their experiences of being refugees have shaped their lives, and what it means for them to become American. Working with “conventional" refugees, asylum seekers, and SIV holders was the easiest way for me to do this. Although “conventional” refugees, asylum seekers, and SIV holders are not a demarcated, "bounded" sub- culture in Portland, they do share similarities in their experiences as resettled persons. All had to flee and came to Portland. Almost all dealt with the UNHCR/American vetting processes; that is, except for SIV holders and asylum seekers, who undergo different screening procedures to be admitted and accepted into the United States. Furthermore, all get help through resettlement agencies in Portland and receive refugee benefits, either at the state or federal level, or both. Because asylum seekers, refugees, and SIV holders all share similarities in 
their resettlement experiences, I have included participants from all three categories, although I have not used the terms interchangeably.

\section{Digital Technologies and Resettlement}

Especially as digital technologies become increasingly ubiquitous, we cannot accept any sort of single, transhistorical understanding of refugees. Digital technologies and Information and Communication Technologies (ICTs) such as the Internet erase traditional physical barriers and thus raise "provocative questions about... the meaning of 'community', identity and public space; the decline of the nation-state; ownership of and access to information," and much more (Panagakos and Horst 2006, 110). Indeed, according to Horst and Miller, the quick development of digital technologies is rapidly becoming "part of what makes us human" and is certainly material and real $(2012,4)$. By this logic, refugees who engage with digital worlds are not simply stripped to their "bare life," but instead have plentiful networks at their disposal, especially through social media; people can communicate with friends and kin both locally and globally, and they can find support and unlimited information online. All of this effectively remolds "refugee-ness" and highlights highly plural, diverse, and deeply personal experiences.

Examining refugee and former refugee experiences is incomplete without considering the digital aspects of life; studies by academics such as Gilhooly \& Lee (2014), Mikal et al (2015), and Sturgess \& Phillips (2010) are useful examples that acknowledge the importance of the digital. Mikal et al note that the internet is highly useful in finding support and gaining independence as refugees adjust to their countries of resettlement, while Gilhooly \& Lee demonstrate the importance of digital technologies for maintaining social networks across national lines. 
Of course, any exploration of (former) refugee experiences must examine practices of identity and belonging; for (former) refugees, it is especially salient to look at the "distinction... between self-identification and the identification and categorization of oneself by others" (Brubaker and Cooper 2000, 15). Identification and belonging are highly subjective experiences; as such, individuals who self-identify as being in a nuanced "situated subjectivity," with a strong sense of self and of social location (Brubaker and Cooper 2000, 17), contrast with the imposed identity of "refugees" to be molded into "ideal [American] citizens" upon resettlement (Cannedy 2011,29). And while refugees have the legal documents supporting their presence in the US, the majority have left friends and family abroad and do not (initially) feel a sense of belonging. This is opposed to other populations who have grown up in, for instance, the US (Boehm 2012) “illegally," or in Dubai (Vora 2013) with no recourse to formal citizenship, but nonetheless feel they belong in the host nation as "social citizens" (Boehm 2012). Understandably, this feeling of belonging (or lack thereof) has important consequences for the ways in which individuals engage with their countries of resettlement, who they communicate with, and how they self-identify and understand themselves, their situations, and how they are situated.

\section{Methods}

This thesis evaluates two very different kinds of internet platforms, Facebook and the Refugee Center Online, to understand what roles they play in informants' self-understandings, feelings of belonging, and sense of being American. I have spoken with 22 men and women across the ages of 18-64 and from various countries of origin. This has allowed me to get a sense of how they use social media to construct their self-identity and how it has impacted their 
resettlement experiences. I have also asked a subsample of these informants to view and discuss the "cultural orientation" aspects of the Refugee Center Online website. I interviewed an RCO employee to understand the website's aims, and used discourse analysis to unpack the website's discourse. I find that Facebook emphasizes a rhizomatic self-conception, while the RCO is more about transplanting oneself and molding oneself to American culture.

The results of this study are the culmination of participant observation and 22 interviews conducted in Portland, Oregon. I conducted participant observation throughout my two and half years of working with Catholic Charities Refugee Resettlement in Portland as a volunteer, interpreter, intern, and case manager. I have worked with, and befriended, many current and former refugees. The daily conversations held as friends over lunch, dinner, and coffee have allowed me to gain much more insight into people's experiences than interviews alone could have.

Participant observation has provided a strong foundation upon which to conduct interviews. Being that this is an undergraduate Honors thesis and therefore quite preliminary, I largely used convenience sampling to recruit and find interview participants. Thus, I have sampled widely and explored what variables and patterns could arise. I had somewhat of a purposeful sample: I included an (almost) equal number of men and women, as well as made sure to include people from a mix of countries, cultural backgrounds, and age ranges. From my work with Catholic Charities, I made friends with case managers, community leaders, and current and former refugees. I therefore easily connected with potential participants to interview_-friends, friends of friends, coworkers, and community partners. In particular, an Iraqi community leader connected me with many Iraqis, who made up a large portion of my sample. Of the 22 people I interviewed, 11 are originally from Iraq ( 2 of whom are from Iraqi Kurdistan), 
2 from Somalia, 2 from Afghanistan, 1 each was from the Democratic Republic of Congo, Latvia, Indonesia, Laos, Myanmar, Syria, and Burundi. Participants were between 18- 64 years old and included 10 females and 11 males. Of the 22 participants, 16 were UNHCR refugees, 2 were asylum seekers, and 4 were Special Immigrant Visa holders. One of these 22 participants is also an RCO employee who was himself a refugee who resettled 10 years ago.

Originally, I had hoped to include persons who had lived in rural and urban areas before coming to the US and to include time cohorts in order to diversify my sample. For the latter, I imagined that individuals who have spent more time in the US likely experience citizenship and belonging differently than someone who has just arrived. Therefore, I aimed to include individuals who had been in the country for less than a year, over a year, and over two years. In practice, 2 of the 22 people I interviewed had been in the US for less than one year; 2 had been here for 2.5 years; 8 have been here for 3-5 years; 4 have been here for 8-9 years; and 6 have been here for 10 or more years, including 2 who have lived here for $20+$ years. As such, my research was effectively skewed toward former, long-settled refugees. Most spend the majority of their lives in urban settings, with 2 having spent time in refugee camps abroad.

Due to a dearth of resources, I could not hire an interpreter and could only interview English-speaking or French-speaking participants (I am a native French-speaker). All were English speaking, with the exception of a French-speaker. Due to my limited resources, I could not speak with people with more limited English skills. Furthermore, all participants were quite highly educated and finished at least high school, while some had completed PhDs, Master's degrees, law school, and medical school abroad. A few have earned their university degrees here in the United States, either to get Associate's, Bachelor's, Master's, Law, or Medical degrees. Undoubtedly, having highly educated, English-speaking participants has skewed my research; 
the omission of perspectives and experiences from less-highly educated refugees (or those with less access to higher education for various reasons) polarizes research and renders this investigation incomplete. This is an unfortunate limitation of my study and will need to be addressed with future inquiry.

Like Kuwee Kumsa, I “disclaim the neutral observer status” (2006, 232); I have worked with many current and former refugees, am passionate about refugee rights and well-being, and have always been fascinated with forced migration from an anthropological lens. Furthermore, as a multicultural individual who holds two passports, I have lived betwixt and between two cultures and countries my entire life. However, I have always had the choice about where to settle and live, and this privilege means that I have never suffered the trauma of forced repatriation or persecution. I have always been drawn to people who have lived between cultures as I have and working with newcomers allowed me to use my privileged position as a white, "Western" woman to help while enabling cultural interchange.

To analyze my ethnographic data, I have employed "grounded theory," a technique to discover themes and theories grounded in empirical data (Bernard 2011, 548). This is a groundup approach, in which I reviewed my ethnographic data closely to evaluate what patterns and themes emerged. As new topics emerged in my interviews, such as questions about communitydriven vs individualistic values, I included them in my subsequent interviews. I could therefore link "data collection and data analysis in one continuous effort" (Bernard 2011, 460). I want to be careful to note that I have not reached any kind of theoretical saturation, although this use of grounded theory has been invaluable in discovering the key themes I explore in this project.

In my exploration of the RCO and its content, I have interviewed an RCO employee who resettled to the United States 10 years ago. I asked questions about the website's content and its 
aims, and about the employee's perception of the material. I have also used discourse analysis to deconstruct the latent, underlying assumptions about "American-ness" the material holds.

Questions of molding “ideal citizens” (Cannedy 2011, 29; see also Cruikshank 1999; Ong 2003) are especially salient here. Out of 22 participants I interviewed for this project, I spoke with 11 about the "American culture" section of the RCO; this choice was determined by the flow of the conversation, the time we had to speak, and whether it seemed natural to veer the conversation to this particular topic. With these 11 participants, we discussed what they liked/disliked about the material, what they thought was useful/not useful, and what they thought of the overall information presented. Interestingly, out of the 11 persons I had explicitly brought up the website to, three had heard of the Refugee Center Online by virtue of their employment with a Portland resettlement agency. No one had used the website as part of their orientation process.

\section{Outline}

In Chapter I, I explore questions of identity. This establishes important context in which people express their feelings of identification and belonging after their resettlement. I explore if, how, and to what degree people might consider themselves "hyphenated-American." What does it mean to be American when one has been labeled a "refugee?" How is the idea of "home" constructed? What roles do longing and nostalgia play in feelings of belonging? How rhizomatic are people's self-identification, and what does this resemble? Refugees are not cleanly ripped apart from "home" (Malkki 1992). Rather, this chapter on what it means to be hyphenatedAmerican highlights the flexibile, changing, and ever-shifting nature of belonging, selfidentification, and rootedness. Thus, it helps to situate the reader in my informants' self- 
conceptions and self-understandings before I explore how digital technologies play a role in resettlement.

Chapters II introduces online resources, such as social media and the RCO. In this chapter, I discuss issues such as how people might use social media to maintain rhizomatic feelings of identity, and how they use it to reaffirm themselves and their beliefs. I then introduce the RCO, its aims, and its ideas. I provide context in which the website functions and explore how my informants have reacted to the website's material. Comparing social media and the service-based resource that is the RCO provides insightful clues into how people can create and maintain rhizomatic self-conceptions. In this chapter, I find that both platforms become "places" in and of themselves for people to turn to and glean information. While social media has a "rhizomatic" emphasis, the RCO focuses on a one-way shift of identity to "transplant" oneself and become American.

Chapter III turns toward how online resources affect feelings of belonging and being American. Here, I highlight how reading news on social media has helped informants understand more of what it means to be American. I further explore how Facebook provides "cultural resource centers" for former and current refugees to glean information. In particular, I examine the closed Facebook group for Iraqi-Americans and other Arabic speaking people seeking event information, discussions, and answers to questions. Turning to the RCO, I highlight how it too acts as a cultural resource center- albeit one of a different kind. As a service-based website that provides informal cultural orientation, I explore how the website constructs American values and belonging. I then highlight my informants' reactions to the material. I highlight here that although the website presents generalized material about American culture, it provides 
informants a way to feel an increased feeling of belonging in the US. Lastly, I provide some initial reflections and possible adjustments to the website's content. 


\section{Chapter I. Hyphenated-American}

My friend Ibrahim, an elder in the Iraqi community who resettled in 2009, has repeatedly mentioned that he feels Iraqi-American. When I asked him about his self-identification, he mentioned, "It's not versus, it's the combination of being two in one." In other words, he does not view his "Iraqi self" and his "American self" as two contradictory, mutually exclusive parts of himself. Ibrahim's explanation echoes what every single informant has mentioned: they feel a belonging to both "here" and "there." In this chapter, I explore this rhizomatic, hybridized selfconception. I demonstrate that a person's longing for home can have important impacts for their feelings of belonging here in the US. Furthermore, I describe how people feel they are hybrid, and what this can resemble. I show that people often feel they belong to people, not places, and that they have mobile roots. I finish by exploring the different ways my informants view being American and how they feel they belong.

\section{Belonging and Identity}

All informants hinted at an organic sense of being in the world that shifts over time - an assuredly hybrid identification. Exploring this self-perception is crucial in setting the stage for a nuanced understanding of refugee experiences. Indeed,

The elaboration of legal refugee status into a social condition or a moral identity does not occur in an automatic or predictable way, and that even people who fled originally from the 'same place' can, and often do, come to define the meaning of refugee status differently, depending on the specific lived circumstances of their exile" (Malkki 1996, 380).

To be a refugee, in other words, is not a moral, static identity that either defines or predicts a person's experiences in any ascertainable way. This is something that is often seemingly 
forgotten in descriptions of refugees as an "anonymous corporeality" (Malkki 1996, 388) lumped together and bereft of individuality. Exploring the plural, diverse ways in which a refugee conceives of oneself and one's feelings of identity is therefore fundamental to any project seeking to understand resettlement experiences.

As Malkki aptly writes, academic discourse surrounding refugee belonging and identity lacks robustness. She writes, "Motherland and fatherland, aside from their other historical connotations, suggest that each nation is a grand genealogical tree, rooted in the soil that nourishes it. By implication, it is impossible to be a part of more than one tree. Such a tree evokes both temporal continuity of essence and territorial rootedness" (Malkki 1992, 28). Of course, these binary oppositions between "rootedness" and "uprootedness"/ "here" or "there" do not necessarily capture the lived experiences of refugee informants I spent time with. Overwhelmingly, the better approach is a nuanced understanding of the ways in which people come to terms with, experience, and manage their "superposed multiplicity of roots" (Hage 2008) - roots, or rhizomes, that "proceed[] from the middle, through the middle, coming and going rather than starting and finishing" (Deleuze and Guattari 1987, 25, emphasis added). I seek to generally outline the ways in which my informants manage and experience their multiplicity of roots in the following chapter to set the stage before developing my discussion on digital resources in resettlement.

On the topic of "identity," I use Brubaker and Cooper's (2000) reformulation of the term to frame my exploration. Arguing that “'identity' is too ambiguous, too torn between 'hard' and 'soft' meanings, essentialist connotations and constructivist qualifiers, to serve well the demands of social analysis" (Brubaker and Cooper 2000, 2), the authors give three clusters of terms as alternatives to "identity": identification and categorization; self-understanding; and 
commonality, connectedness, and groupness (Brubaker and Cooper 2000, 14-21). Throughout this chapter and on, I will incorporate terms such as "self-understanding" and "self-conception" to speak to the ways in which one conceives of one's own identity.

I will furthermore use "external identification" to point at ways in which one's identity is categorized by others. About this term, the authors note that it is the

Categorization of oneself by other. Self-identification takes place in dialectical interplay with external identification, and the two need not converge. External identification is itself a varied process. In the ordinary ebb and flow of social life, people identify and categorize others, just as they identify and categorize themselves. But there is another key type of external identification that has no counterpart in the domain of self-identification: the formalized, codified, objectified systems of categorization developed by powerful, authoritative institutions (Brubaker and Cooper 2000, 15).

About commonality, connectedness, and groupness, Brubaker and Cooper state that commonality means the "sharing of some common attribute," and connectedness speaks to the "relational ties that link people." Groupness is the "sense of belonging to a distinctive, bounded, solidary group.” (Brubaker and Cooper 2000, 20). The authors advance that neither “commonality nor connectedness alone engenders 'groupness.' But commonality and connectedness together may indeed do so." This raises the idea of the "catnet," which they define as "a set of persons comprising both a category, sharing some common attribute, and a network." (Brubaker and Cooper 2000, 20). Throughout the chapter, I invoke this idea of the catnet to conceptualize my informants' social ties and social positions. Brubaker and Cooper's reconfigurations are significant in the nuances they add to questions of identity.

In this chapter, I first examine the longing that many people feel for their countries of origin and how this may play into rhizomatic, hybrid feelings of belonging. I then move into questions of belonging, comfort, and rootedness; here, I explore what a hybridized, rhizomatic 
conception of self can mean for my informants. The conversation then finishes with an examination of how informants conceive of what it means to be American.

As a caveat, I reiterate that my informants are all English-speaking and educated. As such, the rhizomatic experiences of belonging, rootedness, and resettlement that I have laid out here are certainly affected by this positionality. All the informants I spoke with have jobs, are in stable housing, and many are continuing their education. They are, in other words, considered "successful" and "integrated." This is an important caveat to remember, as people who do not speak English, do not have jobs, do not have stable housing, and the like, certainly experience resettlement and their identities post-resettlement very differently. Whether one agrees or disagrees with the notion of "integration" or "assimilation," the ability to speak the dominant language and know how to navigate the country's system has a significant bearing on a person's quality of life.

\section{Longing for Home}

Delving into issues of identity, identification, self-understanding, and groupness (Brubaker and Cooper 2000) upon resettlement leads me first to the notion of longing for home and how this forms a rhizomatic, hybridized identity. Many participants expressed nostalgia for the good parts of their homes prior to resettlement: Hassan, a young Iraqi man in his early twenties who grew up in Egypt, mentioned, "If you go to Egypt, you will never not go back. You will never not go back. Just drink the water, that's what they call it. Drink the water.... I'm in love with the country, even though I'm not from there. It's just so beautiful."

This longing for home is undoubtedly linked to a refugee's need to flee for survival and a better life and their frequent inability to return; although some people could return to the 
countries they left without threat of violence, many remain in the United States with the promise of a strong education, secure job, and stable future. In Hassan's case, he cannot return to Iraq but could go back to the childhood home in Egypt he longs for, although he has decided to remain here for the strong economic and educational prospects.

Certainly, an exploration of (current and former) refugees' longing for the "home" they left is needed in that it provides a backdrop for a person's feelings of belonging in the United States. Take the example of Eva, a former refugee who arrived from Latvia fourteen years before our interview. As one of 12 siblings, she arrived when she was ten years old. She intimated to me that she felt "ripped away" from Latvia as a child when she and her family fled to the United States. When I asked what draws her so much to her country of origin, she noted,

It's definitely the roots...like that's where I came from, that's where my life began, that's where my first memories are...that's like...I don't know.... It's like a feeling....Like I want to cry about it, cause, like, I haven't been back.

Even though she has not returned in fourteen years and has spent the majority of her life living in the United States, Eva places great importance on Latvia as home, alongside the United States. In this way, it becomes clear that this notion of home echoes "the postmodern premise that mobility and deterritorialization are basic conditions in the modern world and that home [becomes] a personal space of identification and habituation, which is first and foremost a cognitive space" (Bek-Pedersen and Montgomery 2006, 96), wherein people "invent homes and homelands in the absence of territorial, national bases — not in situ, but through memories of, and claims on, places that they can or will no longer corporeally inhabit" (Malkki 1992, 24). In Eva's case, it is a cognitive, feeling space incorporating memories of an idyllic childhood, separated from the trauma of persecution, forced migration, and resettlement. Although not totally independent from Latvia's physical locale, Eva's cognitive space of her childhood home is marked by nostalgia for 
the serene aspects of her childhood and the fourteen years that have passed since she was last there. It is a feeling of be-longing -wherein the hyphenated "be-longing" "[emphasizes] the affinity and longing inherent in 'belonging”' (Kuwee Kumsa 2006, 231) - in which Eva feels tied and rooted to Latvia, yearning to remain connected with her foundational home. Importantly, Eva and her family endured persecution, bullying, and poverty as a religious minority - the reasons for which they had to flee. So, although her childhood was likely not always as idyllic as she recalls it, due to the discrimination and poverty her family had endured, the years that have passed since her departure and the trauma of resettlement in a new country have resulted in an invigorated sense of nostalgia and be-longing to her childhood home.



This notion of home as a cognitive space that one longs is quite similar for another participant, Iman, who was born in Yemen to Somali parents and moved to the US ten years before our interview when she was eight years old. Iman's feeling of belonging to Somalia and Somali culture is especially interesting; she did not speak much Somali while growing up in 
Yemen and spoke mainly Arabic. She notes that it was when she arrived to the US that she began to feel more entrenched in Somali culture. She was embraced by the Somali community, she began to wear a hijab, learned to speak Somali fluently, learned to cook Somali cuisine, and created a Muslim Student Alliance club at her high school.

Iman's case highlights that belonging might have nothing to do with actually having been to a place. When I asked where home was for her, she mentioned Yemen and Somalia, despite having faced discrimination in Yemen and having never been to Somalia. When I asked if home was here in the United States too, she responded that she had felt at home here for a while, although she had been bullied when she first arrived and has recently suffered a sharp increase in harassment as a hijab-wearing young Muslim woman. She noted that she was bullied and "othered" upon arriving in Portland, and as such, often got into physical fights with her classmates. She has over time concretized a conception of home as both rooted in space (Yemen and Somalia) but also unmoored from it (having never been to Somalia). And while her conception of home may appear paradoxical, Malkki reminds us that "To plot only "places of birth' and degrees of nativeness is to blind oneself to the multiplicity of attachments that people form to places through living in, remembering, and imagining them" $(1999,72)$. Home in this case is a "cognitive space" embodied in her remembering and longing for places outside of the United States. It is furthermore embodied in her relationships and interactions with the Somali community, as well as with others who categorize her as "Somali." She has been externally identified (Brubaker and Cooper 2000, 15) by people such as her classmates, and has, it seems, embraced the definition and self-conceptualizes as Somali in part because of this.

Iman, Eva, and Hassan effectively highlight that longing for a home they no longer live in exposes the reality that resettlement does not automatically equate to a clean break from one's 
country of origin or former country residence. In reality, one does not break cleanly from one's home; rather, a sense of home shifts, as can a sense of belonging and self-identification. This proves true whether one has not been back in a year, ten years, or even if one never returns. Overwhelmingly, informants pointed to a rhizomatic, hybrid sense of belonging postresettlement, in which they meld cultural aspects from everywhere they have lived, including the United States. This hybridity is an important aspect of their feelings of belonging in the United States, as the following section explores.

\section{Rhizomes, Roots, and Belonging: "We still look in the rearview mirror"}

What exactly does a rhizomatic self-conception mean? How does one feel that they belong, both here and there? My friend Esperance, who fled the Democratic Republic of Congo about 15 years before our interview when the war approached her home, gives an insightful answer. She stated,

I did not leave my country for money, I did not choose to come here. I didn't come on vacation or to be a tourist. Something made me flee. But if things were better, why not return someday? But we are linked because we have roots here. My son was born here. So, we have roots, we are linked. Whether or not I like it, I have two countries.... So we are here, we are good here. We work here...we don't work for nothing, we are here, we are working hands. We work, we contribute something to the United States. And the United States pays us back. But we are always worried about our country... We still look in the rear-view mirror.

Despite not having returned to her country in over 10 years, her feeling of "home" in the Congo remains vibrant - indeed, Esperance and her family "still look in the rear-view mirror." Yet, they meld this "old" home with a "new" home in the United States, where her son was born, to create 
a hybridized, rhizomatic identity. Esperance's feeling of belonging is tied to the labor that she gives back to her "second country," something I will explore later on in the chapter.

This sentiment of "looking in the rearview mirror" is echoed by Mai, a former Lao refugee, who often states she lives the "refugee life":

\section{"Normal" people go for a walk with their dogs to relax. I go on walks to hunt for food! 9 a \#noshame \#refugeelife \#freefood \#laoandproud}

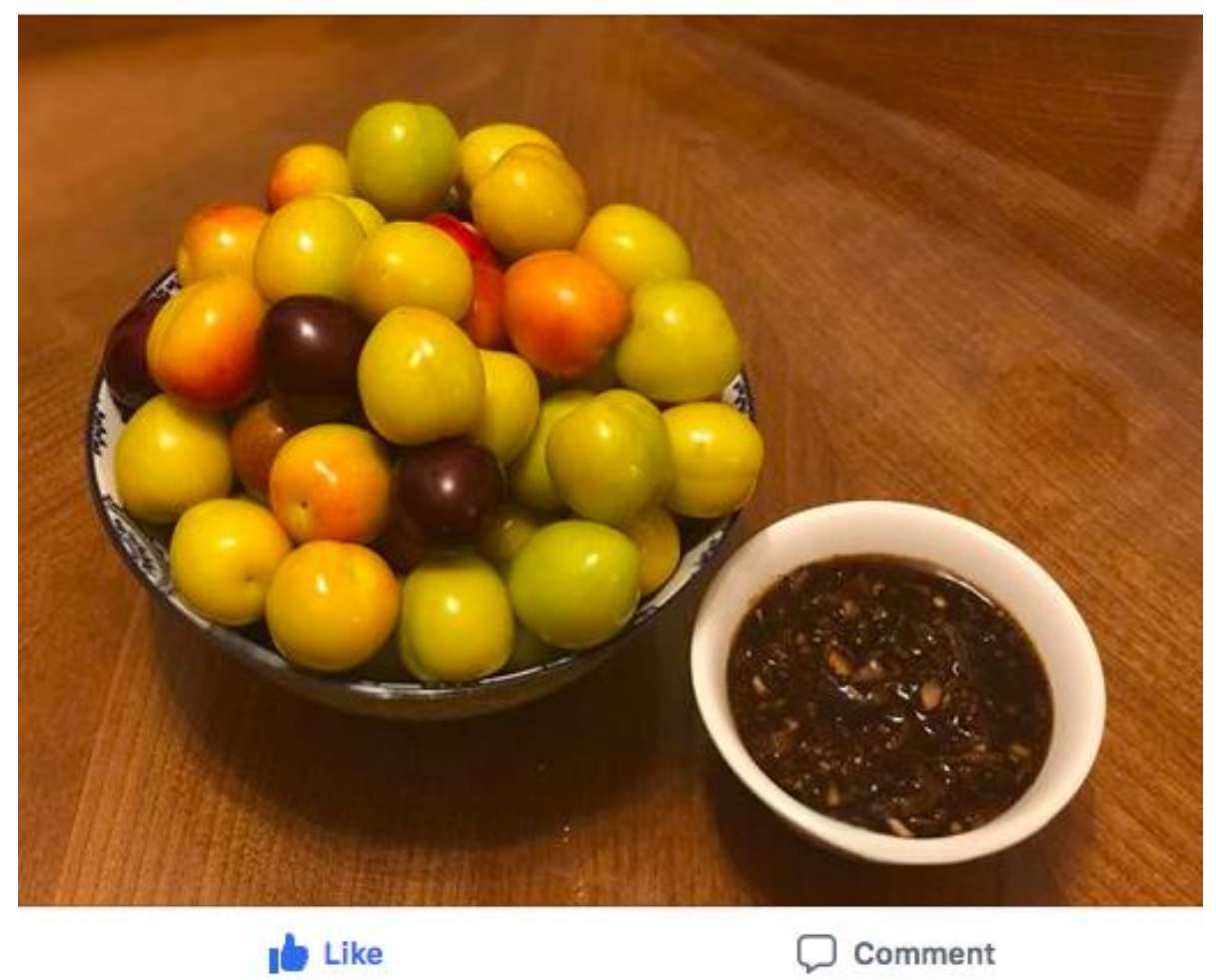

(Snapshot taken from Mai’s Facebook page)

In the above snapshot, Mai ties her gathering of food - picking plums, in this case-to a sense of "refugee-ness" as contrasted to "normalcy," in which experiencing food shortage in a refugee camp is anomalous. Hearkening back to Brubaker and Cooper's quote about the distinction between self-conception and external identification, with the latter often manifested as "the formalized, codified, objectified systems of categorization developed by powerful, authoritative institutions" (Brubaker and Cooper 2000, 15), we find Mai’s self-identification interchanging with the "formalized system" of categorizing a person as a "refugee." She 
manipulates and re-appropriates this categorization into her own self-understanding. Despite having lived in the United States since she was five, and the fact that she is no longer legally a refugee, Mai continues to live the "refugee life" by carrying her history with her everywhere. This is evident in her lingering memories of food shortages and in her gathering food to "relax" as a result, like in the snapshot above.

Mai has noted to me that having been a refugee impacts all parts of her life and that she strongly identifies with her refugee identity. In particular, she emphasized that the traumas of displacement and resettlement have led her to become a community organizer, lawyer, and tireless advocate for newcomers. She proudly lives the "refugee life" and uses her experiences to work positively and productively for others. Mai thus remolds this external identification of herself as a refugee, while simultaneous creating a rhizomatic, hybridized self-understanding/ self-conception/identity (following Brubaker and Cooper 2000: 22).

Mustafa, an Iraqi man who moved to the United States on a Special Immigrant Visa nine years before our interview, evoked a similar thought concerning rhizomatic self-conception. He repeatedly mentioned his love for the United States, a country that welcomed him and provided his family with a safe place to call "home." During our conversation, we spoke about his hybridized identity and I asked how he experiences it. He stated,

There is a [beautiful story] I hear it in Facebook. They say, there is a guy [who] travelled to different country and he have two passports. They told him, which one do you love? This one or this one? So, like for me, if you told me which one you love more? US or Iraq? I tell them, you ask me like, who you love more, your mom or your wife? So, for me, my mom, it's Iraq. My wife, like US. Both of them, I can't live without them. But for me now, if they ask me for US to go to serve in the military, I will go ahead I don't have a problem with that. Because, you know, they give me good life. 
This analogy is quite fascinating for many reasons: first, in comparing the United States to his wife, Mustafa demonstrates that he feels comfortable and at home here. Second, it is interesting for the notion that the United States, his "new home," is just as essential as Iraq, his "foundational home," and that the two parts of his identity can come together and become so integral to his being. What Mustafa describes certainly is not an uprooting or a feeling of having to choose between "here" or "there." Rather, what he seems to highlight is a notion of being both "here" and "there"; it is loving both the home that nurtured him like a mother nurtures her child and the home that entered his life later on but that is just as central—just as he can love both his mother and wife at the same time, albeit in vastly different ways. Mustafa's ties to Iraq are akin to ties to a living relative and they continue to influence his life and identity in meaningful ways, echoing Anderson's argument about the centrality of fraternal and familial ties in nationalism $(2006,7)$.

Other informants highlighted the difficulty of feeling like they belong, but the importance of having a rhizomatic identity in feeling at home here. Ibrahim arrived to the United States about ten years before our interview and had been a respected psychiatrist in Baghdad before having to flee assassination threats. He stated,

There is this confusion of identity and where is home and adjustment, you know, that's a whole process, especially that we are traumatized. So, developing a new identity takes time, for some it will take years, many never develop a new identity.... It took me a few years to define, because I need to define my identity, like OK, I still belong to Iraq, that's my roots, but then I identify... with America.... So, identifying with the, America, as my new home, yes it took me a few years, but I'm stable now on developing that identity. It made it easier for me, I told you, to have this identity, developing this new identity as root-Iraq, new home-America. 
To use Ilcan's words, “As a term, 'settlement' tends to imply an established order of things.... However, settling in a place is a profoundly unsettling social activity" $(2002,90)$, which Ibrahim eloquently expresses. To ease this "unsettlement" Ibrahim keeps art pieces in his home reminiscent of his experiences a former refugee; notably he keeps a piece of wood with some netting over the middle with branches protruding out of the netting. The netting seems to symbolize a new beginning in resettlement, thus distinguishing his roots in Iraq from his new home in America. He also noted,

Just...imagining or having myself identifying with the two rivers, Columbia and Willamette. So, I am from the land of the two rivers-Tigris and Euphrates, and here it's the land of the two rivers. So, that made it easy for me.

Using a comparison of the two rivers to tie his Iraqi roots in with his life here is figuratively bringing Iraq into Portland. The rivers that come together, the Willamette and the Columbia, and the Tigris and the Euphrates, tie Ibrahim's identities into one and render his belonging here more tangible. The symbolism of the tree trunk divided in two by netting similarly unites the two halves of his identity into one physical item. And similar to a river's flow which never ends, we are reminded that "no settlement is ever complete. It is always in a process of settling, unsettling, and resettling" (Ilcan 2002, 3). While Malkki provides the rhizomatic plant metaphor, Ibrahim expresses his sense of self through a liquid metaphor — both of which highlight the fluid, flowing, and ever-shifting nature of self-conceptualization.

Some informants use this rhizomatic self-understanding as motivation to help their communities. Ali is now in his late twenties and resettled to the United States in 2010, having grown up in Saudia Arabia and in Egypt. Although he has not lived in Somalia, he strongly identifies with his Somali heritage and has become a community organizer in Portland. He mentioned, 
Since I lived here for 8 years, so pretty much I know the American culture. I know everything about them, their laws, their system, their culture.... Pretty much it's like me in the middle, so let's say Americans are here, the Somali... so I'm in the middle. To make the Americans understand our culture, to make the Somalis understand American culture. So I'm in between, that's how I feel about it.... I'm like, you know what, I'm here for a reason, to get my citizenship, my college degree... and help with the Somali community. That's when I start to get involved with a lot of Somalis and helping out and going to events.

He makes an interesting pronoun choice in referring to American laws as "their" laws, rather than "our" laws, perhaps signaling a hesitance to wholly align himself with "American-ness." Nonetheless, Ali's call to be a mediator between the Somali and American cultures demonstrates his experiences in the United States as being betwixt and between the Somali and American cultures - not only belonging to one or other, but to both at once. He considers it his duty, then, to be a community leader and use his "within and in between" -ness - his rhizomatic identity, self-conception, and sense of belonging, in other words - to benefit the communities he is part of.

From these vignettes, then, we find a rhizomatic conception of "rootedness," a conception of roots that travel with the person as they move throughout time and space. Indeed, to use Hage's words, “For many people, a greater sense of rootedness does not mean a sense of being locked in the ground, unable to move. On the contrary, roots often are paradoxically experienced like an extra pair of wings....They are not roots that keep you grounded, they are roots that stay with you as you move" (2008). People do not shed their identities and origins to make way for a new, American self-understanding/ identity. Rather, these statements highlight hybridization and a rhizomatic conception of rootedness, identity, and belonging. 


\section{People, not places}

Belonging and a rhizomatic self-understanding can furthermore be deeply embedded in social relationships; as Mai points out, home is:

Wherever my family is. Because there is no building, no specific location. The people that I love - it's a refugee mentality - the people that I love, that care for me, that I care for them. That's home. It doesn't need to be in a specific building, location, or place, right. Because, for us, that can go away. That has been taken away... It's not the tangible stuff, it's what that's in your heart. That's why a lot of refugees, when you speak to them, it's always about heart.

Certainly, this hearkens back to the notion of home as a "cognitive space" (Bek-Pedersen and Montgomery 2006, 95) that is "primarily relational and contextual rather than scalar or spatial" (Appadurai 1996, 178). It is a sense of belonging and rootedness as constituted by people, safety, and opportunity, rather than tied to a specific place.

A few informants also mentioned that they belong to a ".5 generation," as Mai described it. Much like Boehm (2012) highlights, it is being "betwixt and between" and feeling like We're not fully American, but we're not fully Lao.... The reason why it's a .5 is that you are never truly one-you're not accepted in either world-fully. So, never fully American, naturalized, but never truly American, because my accent, my skin, everything... will always tell me what I am.... Because you're never fully full. Two halves.

While Malkki (1992) and Deleuze and Guattari (1987) write about being both here and there, Mai seems to point to feeling neither wholly one or the other-of being neither truly here nor there because she was once a refugee who was forced to flee and to resettle. Yet, hers is feeling of belonging with people, of groupness (Brubaker and Cooper 2000), in which the neither nor translates into her whole, hybridized self. To this point, she spoke about her "sister-friends" and the people she dedicates her life working and advocating for. She said, 
My sister-friends, a lot of my sister-friends, we are very similar in that way [speaking about identifying as a .5 generation], whether we're immigrants or refugees....A lot of our friends, they've survived war. A lot of people are attracted to each other because of what you've gone through. Whether it's the immigrant story or the refugee story. It's that sadness, the emotion that controls a lot of what we've gone through. That magnetic sharing of both our sorrows and our happiness.

"That magnetic sharing of sorrows and happiness" brings people with similar experiences of feeling neither-nor together to become whole and understood. The trauma of displacement, war, violence, and resettlement is not truly grasped by people who have never experienced it. These traumas seem to draw people together as friends. People who identify as part of the ".5 generation" share their traumas with each other and create a special group of people who recognize one another's experiences. This familiarity educes Brubaker and Cooper's discussion of the catnet: a sense of "groupness" in which persons "[comprise] both a category, sharing some common attribute, and a network" $(2000,20)$. I have often heard people implicitly refer to this catnet, in that their feelings of belonging resided more in their relationships than in any tangible place. Many of my interlocutors feel a certain belonging to people, not place.

This sense of identity perhaps additionally has to do with cultural values placed on family and kin relations, something many informants stressed the lack of in America. Rahman, a former refugee from Indonesia who has lived in Oregon for over twenty years, said:

I'm a man- I'm a father, I'm a lover, I'm a dad, I'm an uncle, I'm a cousin, I'm a nephew. So I have all these relationships that define me. I'm a younger brother to an older brother. I'm my younger brother's older brother. So if he does wrong, it's my responsibility to correct him. If he passes away, those are my children. His children are mine. And so we have these relationships with each other.... So we're all in relationship to each other, there's no kind of selfhood. You know, I'm younger than him, but I'm older than him. So, I have these daughters across the street- they're not really my daughters, but they call 
me pap [Rahman] which means father or uncle. Tio. And I have to care for them, like they're my daughters, 'cause they are. So, we have these familial relationships with each other... In our cultures, it's not so individualistic like here.

Belonging is thus embedded in deeper cultural values that preceded resettlement. Postresettlement, perhaps belonging to people is magnified in the trauma of leaving a country and resettling to the United States. Evoking the concept of a catnet centered on belonging to people not place highlights how mobile rhizomatic feelings of belonging and home can be for (former and current) refugees. They are not stagnant: they are flexible, shifting, and living in their sociality. They move, jump, and stretch across time and space as people develop and maintain culturally valued interpersonal relations.

\section{Feeling American}

\section{A Better life: "We live for our family, not only for us"}

Much of my thesis is centered around questions of whether, and how, (current and former) refugees feel American I asked almost every interlocutor what they think it means to be American, and how they may find it is manifested. Chief among the responses I received had to do with simply being here creating a better life. This sometimes means that people do not necessarily feel a strong tie to the United States in particular, but to any place that would let them resettle. I asked Hassan where home is for him, to which he responded: "Anywhere that makes me live, to be honest now. Cause I lost my actual home, you know. So it really doesn't matter."

For many including Hassan, belonging is the simple fact of feeling safe, of having a job to provide for themselves and their family, and of being able to provide a better life and education for themselves, and/or their spouses and children. Mustafa echoed this sentiment, noting that he would love any country that would allow him to settle. He noted that he feels 
American because of his deep appreciation, and love, for the country that allowed him to come with his family and create a comfortable life. Similarly, Amir and Qasim from Afghanistan came under Special Immigrant Visas about a year before our interview after working for US Army. They both left their wives and other members of family back in Afghanistan. Both men noted that life is difficult here for them, but that they feel they belong here because they are safe, have their green cards, and have jobs to provide for their families abroad. Qasim stated, "We live for our family. Not only for us.... I'm in my bed, but my mind is always somewhere else." Undeniably, Qasim's words highlight “how belonging is not so much a secured and individual affair as an experience of living within and on the margins of social relations in a world of increasing insecurity and uncertainty" (Ilcan 2002, 8) America is "home" as a means to escape violence and threats to their safety, but also as a means to provide a better life for their families in which they are deeply embedded. Hearkening back to Mai's examples, these examples highlight how belonging and identity can be loosely place-based, in that my informants do not feel American because they inherently identify with an American culture; simply being in America and "giving back," as Esperance highlights, is enough to feel American.

Certainly, Ilcan reminds us that practices of movement and (re)settlement are not solely individual, but are centered around, and positioned within, social relations. This brings to mind two Kurdish friends of mine: they resettled in the US in 2015 and stated that they came as refugees to secure a better future for their daughter. Despite all of their difficulties, seeing their daughter thrive in the United States is a large part of what makes their resettlement worth it. They have repeatedly mention that they miss Kurdistan; Sera keeps in daily contact with her sister and mother-in-law who are in Kurdistan and almost returned to Kurdistan to live. In spite of this, they feel they belong in the United States simply by being here and working and raising 
their daughter. In other words, their feeling of belonging in US is centered on their daughter's achievements. Sera stated,

We are not living our life, but trying to... [have] [our daughter] live her life. So, what I am doing is just doing anything for [their daughter], for her age, what she like, what she want to do...I am not thinking about my life. So sometimes I am thinking about myself and I say Oh my God from what to what? But at the end, no, I am saying she is important, so [these] 2 years [or] 3 years, [are] just for [our daughter].

Their resettlement experience and life in the United States has been focused on their daughter's well-being, often to the detriment of their own comfort of living in their home country. Yet, seeing their daughter happy and healthy away from the dangers of their home country gives them direction and purpose and a sense of belonging.

Certainly, this concretizes Ilcan's idea that "For people living with the tensions and consequences of globalization, deterritorialization, and mass migratory movements, 'belonging' to a place, a home, or a people becomes not so much an insulated or individual affair as an experience of 'being within and in-between sets of social relations"' (Ilcan 2002, 2). This is undoubtedly the case for the many informants who feel American simply by living here and providing a comfortable life for themselves and their families.

\section{American $=$ White}

Although this was not a central topic in all interviews, race and how it relates to American identity surfaced a few times and gave some tantalizing clues into people's conceptions of what it means to be American. Mustafa, the Iraqi man who worked for the US Army, stated,

You know in 2003, ...in August, I was working with the 352 civil affairs army unit, so there is some sergeants they told me... 'You know what, I can give you your uniform and 
you can come with us by the chinook and we can take it to US.' ... I told them, 'Really!

How can I go to US?' They told me, 'Come on, you are white, and you can wear our clothes, and we can take you.' From that day, I say, 'OK, I need to go to US.'

Mustafa was told he could easily jump on a US Army helicopter, move to the US, and blend in because of his light skin. In other words, the sergeants hinted that Mustafa's light skin renders him "unmarked" and "invisible," and able to move seamlessly between two countries "undetected." Of course, the reality is much more convoluted and layered than this: historically, "whereas immigrant groups such as the Irish and the Jews could over time be assimilated by becoming middle-class and white, groups from outside Europe have... existed on the outside or in some borderland between the white and black ends of the racial continuum" (Ong 2003, 71). Thus, as Neda Maghbouleh writes, Iranian-Americans and other Middle Easterners continue to be "[positioned] at the limits of whiteness" $(2017,8)$. And, while they may be "legally white," they are nonetheless racialized, "browned," and "othered" in their everyday lives (Maghbouleh 2017, 8). Similar to Iranian-Americans, Middle Easterner refugees are

Indeed white by law. Yet, at the same time, political constructions of Iran [and the Middle East] as a deviant, illogical, or criminal state are suffused with non-white racialization observable across each level of American society (Maghbouleh 2017, 7).

This non-white racialization and orientalism is a central notion that cropped up in conversation with Jamila, a young woman originally from Iraq. Speaking about the travel bans, she stated:

In a minute, [Trump] said, like, I decided to make Iraqi just like go back to their country. *snaps fingers* You don't know what he's gonna say. We're so scared right now because you don't know if [the government] gonna take the passport and stuff like that. You don't know what he's gonna do... That make us like nervous, you know. You just don't know what your future is.

While Jamila is "legally" white, her Middle Eastern origins and her religion doubly "mark" her as an -“other." Although Jamila's legal whiteness should enable her to blend in seamlessly in 
America—as Mustafa's sergeants told him—-her headscarf is a clear indicator that she is a Muslim "other." Hence, we run into questions of White Anglo-Saxon Protestant (WASP) dominance, in which light skin is not the only factor in determining how whiteness gets extended; both Roediger $(1991,2005)$ and Maghbouleh (2017) have explored how persons with white skin—such as Jewish and Irish persons in the $19^{\text {th }}$ century—were considered non-white due to their religion and ethnicity. So, Jamila's Middle-Eastern origins and religious garb push her to the "limits of whiteness," in which she does not fit WASP- dominant discourse.

Iman, as a Somali person of color and Muslim woman who wears a headscarf, is even more "marked" and "detectable." Her brothers, meanwhile, have a different experience:

My brothers, they're boys, you know, they go everywhere, so they went from here to here to here, and they played soccer and basketball. They were friends with everyone, so that's how they know Somali culture. Especially when my brother joined a Somali soccer team... Cause boys pick up things quickly and don't seem as... Somali or like Muslim...they don't look like Somalis or Muslims... [People] would guess your ethnicity, especially for my brothers' case- one he looks African American but has really nice hair, so they kind of question it. They're like, are you mixed? And my other one looks mixed [laughter].

We clearly enter into gendered and racialized discourse about who looks, and does not look, like they belong. Iman's brothers-because they do not "look" Somali or Muslim (read: they do not wear headscarves) and have "nice" hair-are assumed to be a least part white and thus, American. Others, who may "look" Somali or Muslim or who do not have "nice" (straight) hair like Iman's brothers do, will be regarded as "not American,” and may help to explain why Iman does not feel at home here in the United States. Like Ali expressed, "even when you become a citizen, they will say that you were born in Somalia. So regardless, you belong to Somalia, you don't belong to anywhere else." 
Certainly, "The concept of America as a specific racial identity has been and continues to be the measure against which all potential citizens are rated as either within or marginal to the nation" (Ong 2003, 70). According to Devos and Banaji's 2005 study on the racial perception of American identity, their "findings are largely consistent with the notion that White Americans are construed as prototypical exemplars of the category 'American.' In other words, the cultural 'default' value for 'American' is 'White"' (464). And while participants gave more nuanced “deliberate responses, associations reveal a very consistent and robust American $=$ White association" (Devos and Banaji 2005, 463). Yet, it is more than just being "white," as Jamila's example highlights above; we also run into WASP dominance in which the language and religion aspects of the dominant culture dictate who can actually count as "white" (see Roediger 1991, 2005).

Equating "white" with "American" is made very clear in Iman's answer to my question about her having American friends. She responded,

"I do not have a lot of American friends. I have Hispanic, I have Asians, I have what other race...but I don't have any white friends...So odd. I had one in high school." Of note, Iman's phrasing hints at a belief that her Asian and Latino friends do not count as American, while white people do. This equaling of white with American is evident in Eva's experience as well:

When people look at us, they don't see 'immigrant', they just see 'dominant culture', which is a privilege but it also means that we're kind of like, I am swept as an American, and it's like, no, there is a story to me and I'm not just another, I'm not American.... I have a different story and so I don't know. ...I'm still like a former refugee.

By virtue of being white and Christian, she is automatically never expected to be a refugee, while someone like Iman, with her headscarf and dark skin, or Mai, is. Mai stated that she is never fully accepted "in either world," and that she will never be totally seen as an American due to her 
accent, her skin, and her physical appearance. As such, Mai’s feeling of being a ".5" generation, of being betwixt and between two cultures, is in part forced upon her-she is externally identified and categorized, as Brubaker and Cooper (2000) would say. She expresses here that she will never be truly seen as American in outward appearance and behavior, and as such could never be accepted as fully American—whether or not she likes it.

\section{Legal Membership}

In my interview with the employee from the RCO, I asked him why acquiring American citizenship is so important to him. He mentioned,

I felt I was able to say hey, I am a citizen of something. ... I am part of the fabric of what makes this country what it is. Whereas in Tanzania, I was in a refugee camp, so whatever happens in that country, it has little to do with me because I'm not accepted.

In other words, to get American citizenship is to be legally, officially accepted as a member. By virtue of acquiring American citizenship, the employee feels validated, seen, and recognized as a valuable person. He is taken from the peripheries of "refugee-ness," from floating "bare life" (Agamben 1998, 75), into the solid sphere of citizenship - a place from which he feels he can enact change and make a mark on the world. He thus feels reaffirmed as an influential, productive person.

Perhaps citizenship as official acceptance explains why a few people mentioned that they will be American once they get their papers. Take Safiya, a young woman originally from Iraq. She spent ten years in Jordan, five in Egypt, and has been in the United States for three years. As a result of moving so much, she stated that she does not feel that she belongs in any country. She further said, "Here, here, I am not a citizen yet so I cannot consider myself an American."

Similarly, Araz, the man from Kurdistan who has lived in the country for three years, stated that 
he may feel like he is home in the United States when he will get American citizenship. The idea that "legal" membership to the United States will confer feelings of belonging is quite fascinating when we compare these experiences to Boehm's (2012) study about "legal" and "illegal" Mexican-American youth in the United States. Boehm notes that many "illegal" Mexican-Americans are "de facto members of the nation" (Boehm 2012, 136) by virtue of having grown up in the United States. Yet, they are rendered invisible because of their lack of "legitimate" paperwork. They nonetheless consider themselves (hyphenated) American. Refugees, on the other hand, arrive to the United States and can acquire their green cards after a year in the country and can apply for citizenship after five years. Their legal membership is immediate, while their social membership takes much more time. That is, they receive state and governmental aid from their very arrival and occupy a legal category of their own. Yet, they often arrive with little knowledge about the place they will live in, the people, the culture(s), or the country's machinations and legal system. In contrast, the "illegal" "de facto citizens" Boehm discusses are social members (Carens 2013) of the country, who understand the country's dynamics, governance, and culture(s). However, they often do not have any recourse to gaining "legal" membership. It is crucial to remember here that refugees seek political protection from the state; as people stripped of the right to have rights, as Arendt would say, refugees consider legal membership to the state of utmost importance.

In fact, many participants have stated that they may decide to move abroad or back to their countries of origin once they acquire their American citizenship, because of the power of the American passport. Indeed, I recurrently heard informants note that being American means having a certain power. When I asked Sera and Araz what came to mind when they hear the word American, they responded: 
Sera: Like you have a power. Because of your passport. Yeah...

Araz: Yeah. Master of the...all the world. And, the most advanced technology regarding the weapon, medicine, university, everything. Is from America. And you know, is dream for everyone, I think, let's say $90 \%$ of people in the Asian, or Middle East to hold American citizenship and passport. This is gonna give you a power and open so many gate for you.

Jamila, the young woman from Iraq who will soon get her American citizenship mentioned a similar thought:

Free. To be free. And be [respected] wherever you go. Yeah, cause, I have an experience that make me love America. One day, for a few days, [a month ago], I travelled to Egypt and then my visa [in the Iraqi passport] just didn't...[...] oh my god, they don't let us get out of airport, they make us like, um, stay in there for one day and they just like [interrogated us] yeah. So, if you were American, you have passport, they gonna tell you, Go ahead. Yeah...that way I love America.

To be American is to be able to move freely and openly. It is to be respected and to be powerful. In fact, Jamila is delaying her marriage — which will take place in Iraq — until she acquires her American passport, in order to travel without concern. Leyla, a young woman from Iraq who grew up in Dubai, mentions that she loves her American passport because it enables her to visit Dubai freely- something her Iraqi passport did not always allow. In this way, being American is a thing, a commodity, to hold and benefit from, rather than strictly a socio-cultural experience impacting their very identities. So, while "citizenship for the disenfranchised American or the disadvantaged newcomer has always been about more than the possession of legal rights" (Ong 2003, 69), many participants seem to feel that the legal aspect of being American is more central than behaving a certain way to be American. This discussion is, at heart, about being American in the wider world; my participants feel and are unquestionably American when they flash their American passports and move fluidly through border security, whether in the US or abroad. 
While they may not necessarily feel American in their everyday behaviors or traditions, and having the passport places them squarely as American in the world order.

\section{$\underline{\text { Conclusion }}$}

In this chapter, I argued that exploring self-understandings through a rhizomatic lens are crucial in understanding any refugee resettlement experiences. As such, I have delved into the key themes of my informants' self-conceptualization that arose in my fieldwork to provide context before exploring questions of belonging online. Longing for a left-behind home provides a backdrop for one's sense of self post-resettlement. I have highlighted that home can be a “cognizant space” that shifts, much like one's sense of belonging and self-identification after resettling in the US. In the section entitled "Rhizomes and Roots," I built upon the previous section's analysis by exploring how people express their rhizomatic sense of self, a sense of belonging that is both "here" and "there." Among the main themes explored in this section are a sense of "looking in the rearview mirror" while also focusing on life here, a love of country akin to familial love, and a sense of being "within and between" different cultures and countries. I have also investigated how many people feel their roots are tied to, and travel with, people. Brubaker and Cooper's idea of the "catnet" is salient here for illustrating how trauma and cultural values may influence a sense of belonging tied to people, not place.

The ways in which my informants define being American is another key theme explored in this chapter. Many stated that living in America to provide a better life for one's family members gives purpose and a feeling of belonging. In this way, many feel they are American simply by living here and giving their families a strong future, highlighting that resettlement is a very social affair. Furthermore, many informants expressed American as white, entering into discourses echoing White Anglo-Saxon Protestant (WASP) dominance. Lastly, many informants 
feel they are American simply because they have the legal documentation that proves it. In particular, a few interlocutors stated that being American means having the American passport that affords them freedom and power. So, they are American in the world order, regardless of whether or not they feel a cultural belonging.

Now, after providing background information on how my informants experience rhizomatic self-understandings, I move on to explore how these are enabled through social media (mainly Facebook) and the Refugee Center Online. 


\section{Chapter II. Online Resources: Social Media and the RCO}

The first person I resettled as a fledgling case manager was an individual who arrived in Portland after having been houseless for almost two years in North Africa; they had lived in the forest, and slept at friends' houses or on the streets during this time. This individual came to Portland with little in the way of belongings: chief among them was a new, latest-generation iPhone. This is not uncommon; many newcomers arrive with smartphones equipped with WhatsApp, Facebook, or other apps that allow rapid and easy access to widely dispersed social networks.

Panagakos and Horst note that because of challenges such as distance or expense in making phone calls, "Migrants are often on the cutting edge of technology adoption" (2006, 111). Every single participant I have spoken to has acknowledged the significance of digital technologies in their lives. Coupled with this, the wide and rapid expansion of all things digital has made it so that digital technologies are rapidly becoming "part of what makes us human" and are just as material and real as anything else $(2012,4)$. Studying them allows us to expand "the study of how things become rapidly mundane" (Horst and Miller 2012, 29) — an element central to anthropological inquiry.

We cannot understand current and former refugee resettlement experiences without integrating their experiences with digital technologies. The recent UN Convention affirming access to the Internet and declaring "online freedom" a human right (2016) bolsters this claim. Certainly, the "extraordinary impact of new technologies on distant family relationships [is that technologies deliver] the potential to transform ... social deaths to vibrant relationships characterized by the ability to be in touch regularly and even constantly" (Baldassar 2016, 23). People can co-exist in "ambient virtual co-presence" together by "maintaining ongoing 
background awareness of others, and [by] keeping multiple channels of communication open" (Ito and Okabe 2005, 264). This allows for a sense of perpetual closeness between people living far apart from one another.

Having access to the platforms is, of course, another question. Owning a phone or computer can be costly and internet connection is not always available or free. Further, even if one has access to digital technologies, there is no guarantee the people they want to talk to do as well. However, increased accessibility to various technologies and the internet render this less burdensome than it was a few years ago. Further, recall the story I presented earlier. The person I helped resettle had very little in the way of possessions and money, yet they nonetheless prioritized buying the latest generation iPhone before arriving to connect with their spatially dispersed social ties.

In this chapter, I begin by introducing how participants use Facebook and other social media. I ask, how do resettled refugees use social media to reproduce their sense of self and identity through interactions with friends and family, both locally and abroad? Recall that the idea of refugees as "uprooted" portrays "roots that threaten to wither" (Malkki 1992, 32). Do refugees use Facebook or other social media in a "rhizomatic" way to maintain ties with old friends while also meeting new ones here?

I then introduce the RCO. The RCO is another kind of "social media" - albeit one of a different kind that provides information dedicated to helping refugees understand American culture. It is a service-based website that presents how to best "transplant" one's roots to the United States. It focuses on teaching newcomers about life in America, and thus, how to be "good Americans." It emphasizes, in other words, a one-way shift of identity, rather than a 
rhizomatic conception of self. In this section, I place the RCO in this wider context of the US Refugee Resettlement Program and analyze some of the website's discourse.

Throughout the chapter, I invoke the notion of online resources as a kind of "place" in which informants spend time exploring. Social media is a place where informants can express and reaffirm their hybridized selves, while the RCO is a place to learn about transplanting one's roots from "there" to "here." In both cases, the Internet becomes a proxy physical setting in which one can "visit" a "site," and explore and linger in intangible—-but somehow still real— "locations." Comparing social media and this service-based resource provides insightful clues into how people can create and maintain rhizomatic self-conceptions.

\section{Digital Technologies}

All communication is "mediated" and takes place through some sort of medium. Before the technologies we have today, transnational families communicated through cassettes and letters (Baldassar 2016). These were just as mediating as digital technologies are now (Madianou and Miller 2012a), leading Horst and Miller to assert "There is no such thing as pure human immediacy; interacting face-to-face is just as culturally inflected as digitally mediated communication" $(2012,12)$. As such, they argue that we humans mediate "what technology is, not the other way around" (Horst and Miller 2012,29) and that people are already a kind of "social networking site" to begin with (Miller 2012b, 153). Although social media and other media as popular culture are only recently being ethnographically investigated, its basics are already familiar to anthropologists.

Perhaps digital technologies act as a mirror to reaffirm and reproduce ourselves. It can also be a means to transform oneself. The increasing numbers of studies dedicated to refugees' 
use of digital technologies and media explores just these ideas: scholars such as Mikal et al (2015) note that the internet is highly useful in finding support and gaining independence as refugees adjust to their countries of resettlement, and Gilhooly \& Lee (2014) demonstrate the importance of digital technologies for maintaining social networks across national lines.

Miller argues for an academic focus on both the creation of technologies and their consequences in people's lives, in order to highlight diverse and "creative responses" to new technologies (2012a, 392). Ethnography of this sort demonstrates that "not only are we just as human within the digital world, the digital also provides many new opportunities for anthropology to help us understand what it means to be human" (Horst and Miller 2012, 4). And, as Madianou and Miller argue in their book concerning migrant Filipina mothers' use of media to sustain relationships with their children, "focusing on this case of prolonged separation and intense mediation ... [gives] a better understanding of the consequences of new media, and an insight into the very nature of parent-child relationships" (2012a, 2). Or, in this case, it provides a better understanding of both new media and the very nature of refugees' experience of resettlement in America. Studying refugees' use of social media sheds light onto intriguing questions of belonging and hybridization post-resettlement.

\section{Facebook}

\section{Social Media as a Place for Hybrid Self-Identification}

Overwhelmingly, it seems my informants' sense of self interacts in a sort of feedback loop with the Internet. Although they already feel "hybridized" and interact with the Internet in a "rhizomatic" way, these interactions also bolster their feelings of hybridity. Let us return to Eva, 
the young woman who arrived when she was ten, and who longs to reconnect to her Latvian heritage. She stated,

I can't speak the language anymore, I understand it, and ... I really wanna reconnect-I started following a bunch of like pages on Instagram of photographers and people [who] adventure and [study] history ... about Latvia. So I follow quite a bit of Latvian accounts... I'm just trying to see the language, I'm trying to see what people are up to, stay connected to the culture and see what's happening and all their national holidays and like... what young people are doing in Latvia, I want to know.

Recall that Eva mentioned she felt "ripped away" from Latvia as a child; by using social media, Eva can establish a real-time connection to her heritage and can feel instantly connected to a culture and place she "be-longs" (Kuwee Kumsa 2006) to. As such, her use of Instagram to feel connected allows her a more "emic" position in Latvian culture; she can actively explore Latvian young peoples' mundane, daily life from afar and can feel more involved in Latvian culture by virtue of witnessing "Latvian" cultural behaviors, outside of her family unit. As such, and returning to Eva's ambivalence about being American and being told she is "not Latvian/Russian," using social media is an important tool for negotiating the inherent tensions she feels regarding her self-understanding and imposed identification (Brubaker and Cooper 2000).

Khalil, an Iraqi man in his late twenties has a similar experience with social media:

It connects you. I think the connection... like, you look at other peoples' experiences. And, sometimes you learn from it. It just keeps you in check, you know... Like you know what's going on. You know what other people are doing, what are peoples' interests, what's trendy, what's in, you know? You know the cool stuff that's happening. It just keeps you up to date with people, the society, with...everything.... You know, it's my home country, so I'm still interested in...knowing what's going on... and after the war and that kind of stuff. 
Interestingly, Khalil did not state that he felt "ripped" away from Iraq, perhaps because he left when he was in his early twenties, at a much older age than Eva when she left. However, Khalil did state that leaving was very hard and that "If I had the choice, I [would] always choose to stay there. I never wanted to leave. But then I left, and I made something out of it.... I'm a realistic person, I try to adapt." So, Khalil makes an important point to be Iraqi-hyphenated-American; according to him, “I'm Iraqi-American, so like I can't act like a complete Iraqi in America.... I try to combine. I try to, you know, stay in sync, you know, with what I have with my traditions, with my culture, and with the new culture, the new traditions and try to come up with a mix, you know" Using social media is an important way for Khalil to cultivate his hybridized identity and be updated on cultural happenings, behaviors, and trends both here and in Iraq.

And, while it may be tempting to believe that Eva and Khalil have a lack of "tangible" connection to Latvia and Iraq-in the sense that Eva has not physically stepped foot in the country in fifteen years and Khalil has not returned in ten - social media is a virtual reality that acts as a proxy for physical presence in their home countries. It allows Eva and Khalil to live in "ambient virtual co-presence" (Ito and Okabe 2005, 264) with their friends and family living abroad and "hang out," despite not being physically present. As such, social media itself becomes a sort of "place," a proxy for Latvia and Iraq. Eva has noted that she would like to return to Latvia to live for a while now that she would not be persecuted as she and her family had been. However, she has established and created a life here in the Pacific Northwest. Returning to Latvia is not an immediate given and would require intricate logistics: quitting the job she loves, moving away from the family she is close to, and preparing herself mentally and emotionally for a "return"- things she has stated she is not ready to do right away. Khalil, on the other hand, could not yet return to Iraq for security reasons. Therefore, Instagram and 
Facebook's abilities to attune Eva and Khalil to their heritages act as a proxy Latvia and a proxy Iraq to visit and explore when they want, demonstrating that "What has been termed the virtual is more a new kind of place rather than a form of placelessness" (Horst and Miller 2012, 27). Indeed, social network sites can often seem "more... a kind of home than as a type of communication between homes" (Miller 2012b, 156); that is, a virtual site becomes a sort of place in which people can enter, visit, socialize, and dwell. It becomes a kind of "meta-place" of its own, made by bringing many people in many locations together into the one virtual place. This place to meet up and gather thus creates and reinforces my informants' rhizomatic feelings of being both "here" and "there."

Social media as place is the ground where rhizomes can grow. It thereby enables people to reaffirm and grow their rhizomatic self-understandings. Recall Mai who considers herself a part of the ".5 generation." She repeatedly mentioned that she lives in "two thought worlds," reflecting her Lao-American hybridity. When asked what role Facebook has in the context of her thought worlds, she noted:

They're all there. If you look at my posts...you'll see depending on my posts, who likes what....Y You have government, department of justice, you have lawyers, you have nonprofits, you have CBOs, you have international agencies, ... people wanting to be involved in different ways. And then you have my family where I'm posting about my hike and my inability to walk, and then you're like, Oh, my family's all coming out to tell me how fat I am... and then my love for food- I love food so I'm posting food all the time. But it's like traditional food, and that's like, what we share, internationally. Food is, for me and my family, cause [it's] very symbolic of where we come from. There's certain things that are cooked regionally, from tribe to tribe, and so when I find them, whether it's at the temple or I'm in Japan or wherever, I'll post it to make that connected-ness. So we'll have family post all over the world, like OH MY GOD, YOU'RE AT [place]!!!?? 
We find Mai's two "thought worlds" coming together on the social network site: her American thought world and her Lao thought world. Although she cannot be in Laos, social media enables her to connect with people in Laos and Laotian culture, ensuring she never loses her feelings of belonging to them. Therefore, bringing these two thought-worlds together in this "place" not only allows Mai to reaffirm her hybridity, but to grow it as well.

We also see Mai's professional life incorporated into her American thought world; as an immigration attorney in Portland, Mai is quite active in immigration issues. She has stated that being a refugee has colored her entire life and makes her "very much a person of the community, for the community, in the community." Her work is integral to her self-understanding and she works and socializes with many government officials and other professionals in her field.

Therefore, while scholars such as Broadbent (2012) have highlighted the ways new media technologies blur the spaces between work and home, for Mai, this is just a reaffirmation of her life.

Facebook also becomes a way for participants to easily share the private intricacies of their daily lives more ease and immediacy. Mai's melding of the different thought worlds —of work and American life, and of Lao family life, food, and connection — highlights social network sites" power to "[bring] together in one place what had been separate networks" (Miller 2012b, 147), reifying her hybridized self-understanding. And, these separate networks brought together highlight the heightened domesticity of social network sites: "What is emerging in the public space is a sense of the interior -that is the private space of the individual externalized onto this digital domain" (Miller 2012b, 156). In other words, social media allows mundane, intricate, often intimate details of daily life to be more easily shared, and to a wider audience. Indeed, Mai considers Facebooks to be a place for her to be fully transparent about her life and thoughts; she 
stated, "I don't hide anything. The good, the bad, the ugly. When I'm angry at the government, when I'm pissed off at the president's policy_it's out there." Thus, she shares her daily goings on, thoughts, experiences (such as the ones with food in chapter I), many of which are "trivial, inconsequential items about the day's events that are more like communication between people who are co-present in the same home" (Miller 2012b, 156). Although Mai may be a former refugee with family living all over the globe who she cannot easily physically be with, "One ironic effect of the increasing transnationalism and cosmopolitanism of migration is that [social network sites] are also in the vanguard of creating a new form of domesticity" (Miller 2012b, 156) and place that people can inhabit, rather than simply communicate in. Facebook and other social media become a personal, domestic space and this domesticity then, gives Mai a space to share, reaffirm, and add to her hybrid identity and self-understanding.

Another way in which social media becomes a "place" for hybridity is in Ali's use of Facebook.

If I see people, I just go through their profile pictures and if I kinda like their personality, what their topic on their page and whatnot. I just add them.... There's people that I've never met them in real life. And I've been knowing them for over two years. We are very close to each other... some of them they live in Norway.... Some of them they live in London. One of them she lives in Ohio- I've never met her in my life. That's why actually I'm going to Ohio, for a soccer tournament... So I might as well just go there and this person that I've never met that I've known over 4 years, just to go see her. Ali has made numerous friendships with Somali (current or former) refugees all over the world. Much like a physical space in which people can meet one another and get to know each other, Facebook is a place for Ali to make deep friendships. Notice that the friends he speaks about here are all Somali (former or current) refugees who live outside of Somalia: these are people who have lived similar experiences of fleeing and resettling in another country. While Ali has 
many friends, both American and Somali, in "real life" outside of an online context, he reaffirms his hybridity by connecting with other people with hybridized, hyphenated-Somali backgrounds. These online friends are close friends, some of whom he has known for years, speaks with regularly, and visits. Note, however, that Ali wants to meet his friend in Ohio face-to-face, rather than leaving the relationship entirely "virtual." So, although social media becomes a place, we are embodied beings who value tangible, physical co-presence with others; social media as place does not entirely eradicate the value placed on being physically close to a person. Nonetheless, social media is akin to a place where Ali and his friends (although separated by many miles) can meet, come together, establish bonds, and share and reaffirm their hybridized self-conceptions; social media is an invaluable way to both create and maintain catnets. This hearkens back to the feedback loop mentioned at the beginning of this section: participants interact with the Internet in a rhizomatic way to create and maintain connections, thereby enhancing their already hybridized senses of self.

\section{On "Being Real" and Reaffirmation Through Social Media}

Recall my assertion in the introduction that Facebook (and other media/Internet usage) is about "being oneself" as a whole, and that it is a way to recreate and reproduce oneself, one's networks, and one's ties. Indeed, Horst and Miller (2012) mention that "Online [people] can bring out the person they feel they really are, which was previously constrained in offline worlds... It is [often] only on the Internet that a person can finally become real" (Horst and Miller 2012, 15). This is certainly the case for many informants who dealt with homesickness and loss of status upon resettlement. 
Take Mina, the young Syrian woman who came as an asylum seeker five years before our interview. When I asked her if she used Facebook and other social network sites often upon resettling, she stated,

It's actually really interesting. When I was in Syria, I used to use Facebook but not really that much. Like, whenever I have time... whenever I have some free time, I just surf Facebook or whatever. But when I came here, because, like, I go to school and I feel so dumb and unworthy, then I open my Facebook and I feel smart again and communicating with my friends again. And like you won't believe it- I would just like, ... like my sister and my mom and I had a mutual room when we were living at my uncle's house, so like, I would wake up in like the middle of the night and hide my phone under the blanket, just so my mom does not see it but I...actually sleep and wake up on their time just I can talk to them. Like, because like, when here it's night, there is morning. Just so I can talk to them and feel good again about myself. I got really addicted to Facebook when we first came here. Like, when I had no English. When I was in Syria I felt like very important, very involved, very popular, and that smart, nerdy kid in Syria. But, and I was like very outgoing, always talking in events or...everyone in my school knows me. And then I came here and start distancing myself, like don't have any friends. But then, like, when I talk to my friends, I like kinda get my dopamine...dosage for the day. I got really addicted to it.

Mina had repeatedly mentioned that she was a popular and outgoing teenager in Syria before seeking asylum in the US. She was busy, involved with after-school activities, and had a full social life. Post-resettlement, however, we find Mina feeling inadequate and lonely. She reveals that she suffered from a lack of voice and was "limited in [her] ability to exercise control over [her] circumstances" (Mikal et al., 2015, 1324); that is, a loss of social status and social capital (Mikal et al., 2015, 1324) because she did not speak English and suddenly found herself in a wholly new socio-cultural milieu. The juxtaposition between her lack of social media usage in Syria when she felt confident and her use of Facebook when she resettled highlights its 
importance for her; it was a way for her to feel "smart" and "worthy" again. It brought her right back to her friends and reinstated the social capital she felt she left behind in Syria. So, perhaps like Eva, who uses social media as a space to "inhabit" and feel close to her Latvian culture, Mina used the platform as a space to escape from the difficulties of resettlement and "bring out the person [she feels she really is]" to "finally become real" (Horst and Miller 2012) again.

As Mina gradually felt more confident in herself, improved her English, and adapted to her life here, she mentioned that she does not use Facebook much anymore:

Like, now I feel important again, I feel worthy, I feel like I do belong here, I can understand people. Like now, I barely use [Facebook]. Even my best, best friend for like 13 years that lives in Syria still, and she was my best friend for 13 years, like now, I either talk to her once a month or like once every two months. Like, now, it's like whatever...

It was when she was feeling her lowest that social media became a space in its own right, a place for her to inhabit where she could rely on friends and feel like herself again. Perhaps this highlights the importance of anthropologically studying the consequences of digital technologies: in their study focused on refugees' use of the internet, Mikal et al., note that "If an event is deemed negative and an individual lacks coping resources, the event is perceived as stressful and can lead to diminished mental and physical health. Mental health outcomes of chronic stress include depression, anxiety, cognitive impairment... and insomnia" $(2015,1321)$. Yet, as we see in Mina's case, social media provides a coping resource for people feeling isolated, lonely, and invisible. It is furthermore a powerful means for people to reaffirm themselves and "feel real"also aptly demonstrated in Ginsburg's (2012) study to do with disabled peoples' use of the Internet and other digital technologies.

Ibrahim, the older Iraqi man who resettled in 2009, provides another significant example of the ways in which people reaffirm themselves and their connections online. Ibrahim was a 
respected psychiatrist and a prominent activist in Iraq, and the latter activity forced him to flee. He cannot practice psychiatry in the United States, as he has been unable to gain equivalency here for the degrees he acquired in Iraq — an all-too-frequent occurrence among refugees and asylum seekers (as well as other migrants). While he has suffered from being unable to practice psychiatry here, he dedicates himself to being an assiduous, prominent activist, works hard as a cultural mediator and representative for the Iraqi community, and works in mental healthcare. Facebook is a meaningful way for him to reaffirm himself online and to spread his message and beliefs. I asked what makes Facebook so important to him:

Make my opinion public. Well, again, because it's two parts. Because, I'm still interested in things in Iraq, so definitely that's my way of communicating, through Facebook about Iraq, right. Uhh, for United States, again, because it became the...I found that it's the easiest way to communicate with people, your concept, you propagate your mission, your concepts, your ideas, you get into discussions....But then, when there are dialogues and discussions, or I need to advocate for some of my beliefs and ideas, I would use Facebook.

The mission-propagation and discussions Ibrahim engages in are meaningful self-expression, because his activism is a central aspect of his sense of self. Many people that he communicates with are (Iraqi) activists themselves - people he would not be able to dialogue with as easily about issues facing Iraq were it not for the ease of social media. In this way, he continues the discussions and activism he engrossed himself in prior to leaving Iraq and engages with an important part of his past. In other words, he brings what was "there," "here" and reaffirms a rhizomatic sense of belonging and self-conception. 


\section{On Comfort and Social Media as a "Friend"}

Social media's never-ending presence, its ability to always be here and "on," means that it often acts as a "meta best-friend" (Miller 2011, 2012b). Indeed, Mina used social media as a meta best-friend when she mentioned she used Facebook much more often when she first arrived. Esperance, the woman from the Democratic Republic of Congo who has lived in the US for almost ten years, concretizes social media as a meta best-friend as well. She noted that she uses Facebook as an album for her photos, to de-stress, to feel complimented by friends and family, and to remain connected to people and to her country of origin. She posts photos of herself and her family, and videos in which she records her thoughts. She stated,

Sometimes, it's anti-stress, because there are people who post funny things, you know.... You have to adapt to life here. And adapting to life in the United States is primarily about working... You can't do anything without working. So, when someone wants to let off steam [se défouler] or anti-stress on Facebook. Everything is posted there [you can find everything there].... It's like drinking a glass of water or a glass of wine when you are really exhausted.

Fleeing the DRC, living in a refugee camp in Tanzania for ten years, and resettling to the United States was hugely traumatic for her and her family. Getting acclimated to the United States was just as difficult. Throughout our conversations, Esperance often brought up work; she noted that work is central to being, living, and belonging in the United States. She mentioned, "We work, we're not.... We don't live for nothing — we're here, we are working hands. We work, we contribute something to the United States. And the United States pays us back." Combining this with the recollection that Esperance and her family "still look in the rearview mirror" to the DRC, it is no wonder that using Facebook and social media is a means for Esperance to relax and disconnect from the demands of life. It is always there when she wants it or needs it and will always provide some respite. It is a "meta best-friend to turn to" (Miller 2012b, 158) that gives 
Esperance the space to let off steam, to be herself, and to craft an image of her life through photos and words — an image affirmed through others' comments and likes.

Social media as a meta best-friend demonstrates that people use the platforms in a multitude of ways to satisfy different needs. Indeed, social media sites such as Facebook "[exhibit] a surplus communicative economy in that people seem to do all sorts of things with it that are hard to reduce to some simply communicative need or any other sort of instrumentalism" (Miller 2012b, 158). Thus, it becomes even clearer why social media plays an important role for current and former refugees' well-being. As a meta best-friend, social media allows people to know that they are not alone and that their support groups are never far. If they need support or conversation, there are always ever-available platforms on which this can take place.

Perhaps simply knowing that social media platforms are there, that people have meta best-friends, is just as important as having people to turn to. Mikal et al., note that "individuals need not necessarily activate their support network to derive benefit from it. Simply knowing that support is available is often sufficient to buffer an individual against the negative effects of stress" $(2015,1321)$. Esperance's example provides insight in this regard. She uses Facebook as a photo album for herself, for her family, and for friends:

Even if you lost your phone, you see, you still have the photos. It's a photo album, I post videos, I post photos. Alright- there are some people that say 'if you post photos of you eating, it's not civilized,' but it's all part of journalistic life... That's the feeling of Facebook.... And when people comment, 'Oh you look good, what were you doing?' it feels good, it feels good.

Esperance enjoys Facebook as a space to post about herself and her life. These are not photos intended for specific people to see and are not strictly a means for updating her friends and family. Rather, her use of Facebook in this way highlights its usefulness as a place to freely store precious photos, but also again highlights its position as a meta best-friend that she can share her 
life with. If Facebook were simply a place to store photos, she could create private albums only accessible to herself or close friends and family. Instead, this is posting "out there"-past her close friends and family_into extended networks and people she may not even know well. It is a "journalistic" approach to sharing her life, in which she uses her page as a gallery to highlight moments in her daily life. The photos are not posted for any specific people, but rather, for Facebook at large, and the resulting comments that arise on her photos bring her comfort, make her feel good, and connect her to friends and family "out there." In this way, Facebook as meta best-friend provides familial comfort; it becomes a kind of living room that people can use to store precious photos and memories. One knows this meta best-friend will hold onto those photos and memories, keeping them safe only a couple clicks away.

Safiyah also reported using Facebook as a meta best-friend to let her feelings be known "out there." She said, "Sometimes you know when... you are feeling bad and you want to tell someone something in [an] indirect way, you just post it you know. That's what I do sometimes." Safiyah, like Esperance, communicates to Facebook at large. The act of projecting her emotions and venting, almost like she would to a friend, allows Safiyah some relief when she is sad, angry, or unhappy. Someone, or rather the collective "someones" of Facebook, will know of her feelings - even if it is not the person the post is intended for-creating a space for her to express herself. Hearkening back to the idea of the living room, Facebook becomes a place for Safiyah to come into, feel at home in, and express herself. This brings up Miller's idea that, "Instead of seeing Facebook as a means to facilitate friendships between people, many of us use friendships between people to facilitate a relationship to Facebook itself” (Miller 2012b, 158). Social media itself can be comforting and familial, providing a space to be reaffirm oneself. 


\section{Kin- and Friend- Work}

Given that digital technologies allow for "ambient virtual co-presence" (Ito and Okabe 2005, 264), notions of kin work become salient — a term which Di Leonardo defines as "the conception, maintenance, and ritual celebration" of kin ties $(1987,442)$. She highlights that maintaining such ties requires intentionality, determination, and time. She states, "We tend to think of human social and kin networks as the epiphenomena of production and reproduction: the social traces created by our material lives... But the creation and maintenance of kin and quasikin networks in advanced industrial societies is work" (1987, 443, emphasis in the original). Digital technologies have proven to be an easy way to communicate, "do" kin work, and engage in transnational care (Baldassar 2016). Hamid, a former journalist in Iraq who fled after threats to his and his family's safety almost four years before our interview, mentioned that he speaks with his mother every day.

I speak with my family, and this is funny because my mom she don't have any relationship with technology. So when I moved in 2014, what she did, she collect her retirement salary and she bought a smart phone and she pushed my brother to establish a

FB page for her so she can communicate with me, because she knows I will be on Facebook 24 hours.

Hamid spends a lot of time on social media, seeing how friends and family are doing in Iraq as well as here. As such, his mother's decision to get a Facebook account was the surest way for her to be as close to her son_-digitally_as she could be. Hamid mentioned that they speak daily and call each other every day on the Facebook app_effectively living in ambient virtual co-presence together. Hamid's mother speaks with Hamid's children and wife regularly as well, through him. Hamid's example, then, highlights how "Those family members who 'stay behind' also become part of social relationships stretched across time and space, even though they might never actually relocate or move at all... Both the migrant and the non-migrant can inhabit the same 
social field of relations as well as share the same affective transnational imaginary" (Baldassar 2016, 24). That is, despite never having moved, Hamid's mother feels the effects of transnationalism while still holding on to constant ambient virtual co-presence with her son, rendering kin/friend work not only feasible but ingrained in mundane, daily life — much as though they were together physically.

Despite the benefits of digital technologies, Madianou and Miller (2012a; see also Madianou and Miller 2012b) have demonstrated that such technologies can easily also become burdensome for questions of kin-work. Interestingly, a few of my informants noted that friends and family living abroad accuse them of not staying in touch enough and of not putting in the effort to keep in contact. In other words, they were reproached for their lack of engagement in kin work and/or friend work. Leyla, the young woman originally from Iraq who lived many years in Dubai before resettling in the US, mentioned that she keeps in touch mainly

Through Snapchat. [What about FB?] I do, but not, I don't answer anyone... I'm the worst and then they write, and then the thing is, I post pictures. And then, my friends is like, 'Why you post a picture and then you just don't reply to anyone when they say anything.' ... I have one friend... yesterday she send me a snap, she's like-_'You never ask about me! I always start the conversation, you never talk to me, anything!' And I was like I just sent her two hearts...I really don't know, and I was like, 'How are you?' And I really do care to hear about her, I just, you know, when you are here and you work full time, and then you have a husband and you have a house, it's just too hard to keep in touch.

When "caring through the acts of communication, writing SMS and email, maintaining the Facebook page, and so on, become themselves constitutive of the actual relationships" (Baldassar 2016, 29) like it is for so many current and former refugees, neglecting kin and friend work can effectively degrade relationships. Yet the realities of life often make it difficult to put in the effort to keep in touch, as is evident from Leyla's case. Being tired, feeling like one needs 
to focus on life here-as Araz mentioned_-or a lack of time are all important factors in kin and friend work. Leyla noted that she nonetheless does find it important to keep in contact and I asked her if social media was important to her because it keeps her in touch with people. She stated,

Snapchat... I use it to see what they are doing. I know what they do, they know what I do. I post on my Snapchat. They post on their Snapchat.... It's like everyone-it doesn't have to be like I'm taking twenty minutes to write you.

As Broadbent (2012) and Miller (2012b) note, using platforms such as Facebook or Snapchat are less demanding than "synchronous communication" like phone calls or text messages. They emphasize that by virtue of being "a semipublic act, a posting is not to anyone in particular and so doesn't require or demand the attention of any other particular correspondent" (Miller 2012b, 151). It is typically only when something out of the ordinary happens that Leyla reaches out to friends:

If I see someone doing something, like someone in the hospital, I will talk to them, like hey what's up, what's wrong? My friend she just had a girl baby...I feel so bad, I want to go I want to see her. So she snapped it and I saw the picture and I talked to her. For questions of care, Snapchat is an easy way for Leyla and others to quickly and efficiently show friends that she wants them to know her goings on; she can send snaps, videos, or photos of her daily activities without "taking twenty minutes to write" or tailor her messages to each individual. It is a quick, efficient, and energy-saving way of "doing” care to keep in touch.

Nonetheless, the effective and wide reach of social media like snapchat, Facebook, and Instagram do not substitute the one-on-one kin/friend work that many informants' friends and family desire. This brings me back to notions of American values cited in the first chapter, and how these play into informants' decreased performance of kin/friend work. Safiyah mentioned: 
Sometimes like my friends they tell me 'Oh why you don't talk to us anymore? We miss you.' And then I say 'I swear I'm really busy, you don't know what it is to live in here, especially in here, in the United States. It means that...In the United States, it means that you are busy all the time, working, studying, especially in college because college needs more time, you need to spend more time studying.' And now I know more the system of studying, I know more how should I study and you know so...just so busy, here in the United States, so busy.... Back home, I had time, everyone has time for everything.... In Egypt, when I had a family, we all used to gather on Friday...but here I don't do that anymore.

Here, we see hearken back to the idea of American culture as "individualistic": informants mentioned that Americans often do not spend enough time with their parents and that they do not think about the (wider) family unit as much as the individual. Informants furthermore often expressed the difficulties in acclimating to this approach to kin and friends. In fact, many mentioned that they do not want to raise children here because of it, or that they will raise their (eventual) children with more "community" values like the ones they grew up with. To an extent, Safiyah is engaging in "individualistic" culture by not undertaking kin/friend work because she has had to adopt to the American "busy-ness" of school, work, and life. And yet, it is possible that her actions read as American to others, while she is in fact dealing with a greater class aspect that requires her to work harder and study harder to make more money. Her days of "having time for everything" are no longer applicable in the United States. As such, it may not be that she is consciously becoming more individualistic, but rather has to prioritize to protect herself.

Hamid expressed a similar inclination toward American individualism; in our conversation, he mentioned that he blocks certain people from seeing certain posts on his Facebook wall. Because he increasingly controls his privacy,

Some people they've been mad at me. They're like, 'Hey, why are you keeping hide your news from us. We don't know anything about you.' For that, people they get mad.... 
Some people they even they was following me on Facebook to know my news, and I reach a level right now, they don't need to know all that news, so sometimes I keep it away from them and they start to be mad.... We didn't see your news for a long time, why you do that? Or they try to search and they found themselves blocked and they still have my number and they text me, "why you block us?"

By adopting a value many of my informants find common in America—privacy—Hamid arguably does not perform the kin/friend work many of his Facebook friends would like him to do.

He mentioned earlier that he loves Facebook because he can control his privacysomething he could not really do back in Iraq because people love to talk. He tells people they need to accept his privacy now because "this is the way we deal with things here" in the US. He also mentioned he chooses to block certain persons because he does not really like people back in Iraq to know he is in the United States, both to avoid getting calls about how to get here and also to protect the family that is still there. This rationalization that he needs to protect friends and family, and that they need to accept that this is how things are in the US, gives him an excuse to enjoy the privacy he wants while preserving social relations. Here, then, we see Hamid enjoying an "American" trait, but shifting the blame for his diminished kin- and friend-work on having to survive in a new setting. He now has an excuse to protect himself and prioritize who he connects with regularly, without sacrificing relationships. In short, what reads as increased "American-ness" may also be Hamid reaffirming himself in ways he could not before coming to America, leading his friends and family to lament his lack of kin- and friend- work.

One's hybridization might involve conflicting identities. While Hamid is certainly hybridized and his online practices certainly may divulge some American tendencies, there is also a question of rhizomatic segmentation to be addressed. That is, the "collapsed context" of social media makes it so social media users are "forced to grapple simultaneously with otherwise 
unrelated social contexts that are rooted in different norms and seemingly demand different social responses" (boyd 2014, 31); as such, certain content is fit for certain group of people, while being unfit for another. The meta best-friend that is social media thus segments into multiple friends who receive and share different content. Therefore, perhaps the question is not only whether or not Hamid reaffirms his hybridity online by neglecting to do kin- and friendwork, but of how the rhizome buds and splits from a single mass that links "here" to "there" into separate plants that link a person "here" to "there" and "there" and "there." Unfortunately, I do not have the answer, and if I were to continue this research, this is most certainly an avenue I would follow.

\section{The RCO: Cultural Orientation Online}

Studying current and former refugees' social media usage sheds lights onto how people use social media as a "place" to create and maintain a hybridized, rhizomatic identity. Now, I turn to the Refugee Center Online (RCO), an online site of a different kind-one that provides information and services. This distinction is key; while using social media is about reaffirming oneself as a whole, the RCO as an online place focuses on teaching newcomers how to integrate into American culture. In other words, while social media is rhizomatic, the RCO is about transplanting oneself from "there" to "here" with a focus on living fully in the US. It is a oneway shift of identity.

I have a particular interest in the American "culture" and "identity" segments of the website. In this chapter, I introduce the website and how people use it to explicitly consider American values and reaffirm their beliefs in them. I ask, what is its aim? How do respondents 
react to the information? Do they reaffirm themselves and their own values through the website's material?

I begin my discussion by explaining certain key machinations of the US Resettlement program. I have explored its mechanics prior to refugees' arrivals in the introduction; here, I shift the focus to the services refugees receive post-resettlement to the US. I then introduce the RCO as an organization, highlighting that it is a non-profit organization that provides informal cultural orientation materials to newcomers. I lastly explore how respondents have reacted to website, highlighting that it can echo social media in being a place for one to reaffirm one's beliefs in "American values."

Upon arriving in Oregon, refugees are assigned a case manager who works with one of three refugee resettlement agencies: Catholic Charities, Lutheran Community Services Northwest, or SOAR. This case manager is in charge of providing newcomers with housing and connecting them to food assistance, health insurance, ESL classes, and job placement programs. The case manager follows their "clients" for up to 8 months and provides assistance from two programs - the Reception and Placement $(\mathrm{R} \& \mathrm{P})$ program at the federal level and the Refugee Case Services Project (RCSP) from the state.

For the purposes of this discussion, I streamline my focus on the initial R\&P program. This federally funded project lasts 90 days. Within this ninety-day period, refugees are given a one-time sum of money (about $1000 \$$ per individual) to spend on housing, food, etc. Case managers must assure individuals receive their social security cards within this time frame, must arrange medical visits, language classes, job placement classes, and must register children in school. 
Of particular importance, each refugee must complete cultural orientation $(\mathrm{CO})$ classes within the R\&P period. These $\mathrm{CO}$ classes are meant to be a quick introduction to life in America. This is the context in which the RCO emerges: the website provides "informal" CO information about life in America that newcomers can freely consult at will. "Formal" CO material is crafted by organizations such as Cultural Orientation Resource Exchange (CORE), which provides resettlement agencies with $\mathrm{CO}$ materials to teach newcomers. I introduce the organization here to give context about cultural orientation in the US refugee resettlement system. CORE "conduct[s] research on the background and needs of specific refugee populations. [They] document and share effective cultural orientation practices" (CORE 2018). This particular website was "developed under an agreement financed by the Bureau of Population, Refugees, and Migration," within the Department of State to provide formal CO materials to cultural orientation providers. CORE is run independently by the International Rescue Committee and so the material does not "necessarily represent the policy of [the USDS] and should not assume endorsement by the Federal Government" (CORE 2018).

According to the CORE website (2018), CO content spans a wide range of subjects:

The Role of the Local Resettlement Agency

The Importance of Learning English

Housing

Transportation

Employment

Education

Health and Hygiene

Cultural Adjustment

Budgeting and Personal Finance

Community Services and Public Assistance

U.S. Laws and Refugee Status

Although the amount of class time and manner of delivery depends on the organization, Catholic Charities Refugee Resettlement of Oregon generally teaches 10 two-hour long classes pertaining 
to these subjects over 5 weeks. Of particular interest to me are cultural orientation materials related to American culture and cultural adjustment.

As Aiwha Ong (2003) argues, citizenship is a social process (see also Cannedy 2011). Learning to become a citizen is socially constituted, demonstrating that "citizens are not born, they are made" (Cruikshank 1999, 3). Indeed, resettlement agencies are crucial in molding refugees into ideal citizens (Cannedy 2011, 29), and the CO classes they provide are an integral part of this social process. Although CORE provides formal, official CO materials for resettled refugees to interact with, cultural orientation information is not solely provided at resettlement agencies, as Ong's discussion demonstrates. This is the RCO's case: its goal is to provide general information which newcomers may find helpful — "informal," supplemental CO - that anyone can freely access at any time. It is not contracted by any governmental body, so it relies on private- and donation- based funding.

\section{What is the RCO?}

Citing the Internet and the "proliferation of mobile technology" as their mode of operation, the Refugee Center Online asserts it is the only website of its kind. It works as "A one-stop, comprehensive website that houses all of the resources and information newcomers need to build successful lives for themselves and their families here in America" (RCO 2018a). The non-profit organization was founded by Jessica Marks and Miranda Kaiser, two American women with a profound passion for, and extensive experience in, working with refugees. Kaiser, a direct descendant of John D. Rockefeller Sr., cites that her heritage as a Rockefeller calls her to work to welcome refugees to the United States (UNHCR 2017). The website is funded by various private organizations, such as the Carnegie Corporation, the David Rockefeller Fund, 
and the Rockefeller Brothers Fund (RCO 2018c). Recently, the organization has received a 50,000 dollar challenge grant to expand its operations to Italy (RCO 2018f). The website also encourages private donations from citizens.

The website prides itself on working with refugees and immigrants directly for a majority of the website's functions; many refugee/immigrant translators were employed to translate content, and much of the material is curated by former refugees/immigrants (2018c). Numerous former refugees/ immigrants sit on the non-profit's board, as well as on the Refugee Technology and Advisory Council, which makes up a large portion of "the iterative process of input from newcomer communities" (RCO 2018a). The employee I interviewed from the RCO explained the writing process. He stated,

We have an editor. She does our editing stuff....Prior to RCO being RCO it was more of a volunteer organization. People [came] in and [shared] their knowledge of like what they [knew]. And that's how many pages was written. It was written through the individuals, ...research [and focus groups]. And because it's national and it started that way, it's always been more about a general overview of information.... This editor has a number of years' experience .... but there's so many individuals that are involved, like teachers and former ESL teachers.... So it's built by everybody.... We also work with the refugee committee that does reviewing ... Because [the founders] wanted to put on the most helpful information for refugees and immigrants. And [that] information was more from refugees and immigrants, like what they wanted or other individuals, like their experience with a certain thing. And then [the founder] will have to write it [up] or somebody else will have to write it.

While the headquarters are based in Portland, Oregon, the company's online nature allows it to employ, and elect to the board, people living across the United States - from North Dakota to Florida to Oregon. Everything presented on the website is free to use for anyone who wishes to access it. According to the 2017 Annual Report, the website reached 250,000 users that 
year (RCO 2018c), and the employee I interviewed mentioned that the website currently gets about 80,000 visitors on average per month.

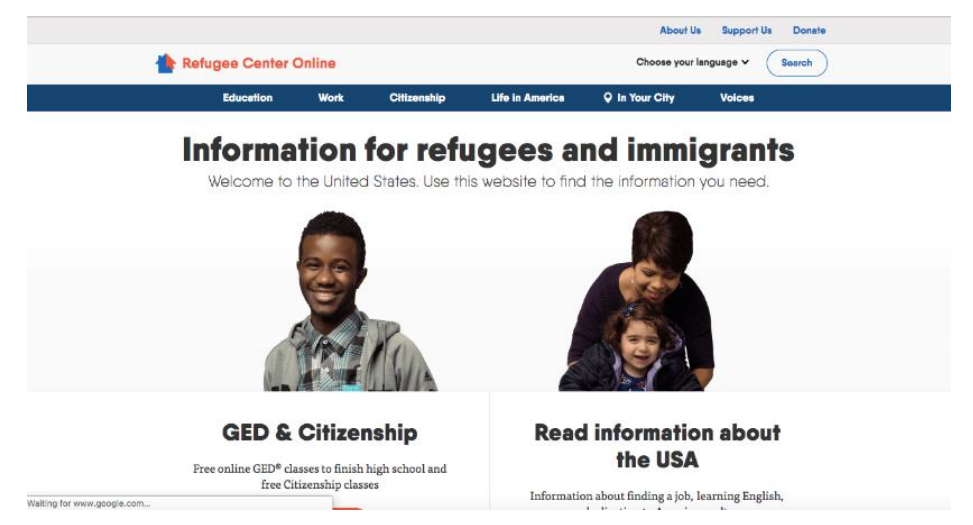

The front page of the RCO

According to the RCO, "Refugees and immigrants often struggle to learn English and face difficulties in finding living wage jobs, adequate housing, healthcare, education, and transportation. As a result, newcomers largely feel marginalized or isolated and are systematically underemployed and economically disadvantaged." (RCO 2018b, emphasis in the original). The website works to offer knowledge and information—informal cultural orientation - to newcomers concerning life in America. The same employee I interview explained,

The way the Refugee Center Online is set up, it's a platform where any refugee or immigrant, any displaced individual that's in the US, can go to and find ... information. From jobs and careers to how to do your [job] interview. Entrepreneurship or how to start a business. Kind of an overview of all kinds of information in one place. Because we can use Google to find it but it's very difficult to find something that you don't know what you're looking for. You don't know the name. ...This one is a website that's just specifically ... geared ...drafted ... produced just for the benefit of refugees and immigrants. And then we write it in an easier language to understand....

That easy-ness of finding a welcoming place (emphasis added) where you can go to and find all this information that's geared to you, it's different than having to go and google 
and try to find how to start a business. ... This is a beautiful platform. It's almost like a mini Google. That's what we're trying to create.

The RCO aims to create a "place" like social media—one in which people can come to, dwell in, and visit to get information. Unlike diverse cultural material one finds on Facebook, the RCO's material is distinctly American. The employee stated,

We try to also educate refugees to know...it's a country where you could get help and we want [them] to take it as a hand up, not a hand out. So that's where we try to empower them to build their own lives — not so much of here we go, we're just going to give you this, so much of like, here's this information how you can actually really become successful.

The idea of being "successful" without getting a "handout" is a neoliberal value — one that emphasizes individualism, independence, and entrepreneurialism. By having the reader understand that the RCO will not provide them with anything other than basic information, the RCO thus pushes the responsibility of being successful onto the reader. As I will elaborate upon later, this is an example of the website's focus on transplanting roots and transforming newcomers into "good Americans."

The website includes tabs labeled "Education," "Work," "Citizenship," and "Life in America." Each of these tabs has subsections to explore, such as information on one's rights as a refugee/immigrant, and material on how to acquire a GED, how to apply for college, how to find a job, or how to apply for asylum/ citizenship. The website also has an "In your City" tab, which allows one to find resources and services based on one's location. The last tab is the "Voices" tab-a section dedicated to articles written for and by refugees/immigrants about various topics. This tab also includes a forum in which people can post questions and get responses from anyone perusing. Additionally, the website offers various online classes such as a GED Prep course, a Citizenship Prep course, and practice tests for each. The website additionally has a translation 
function, which translates the entire website into one of 46 languages, including Somali, Arabic, French, Kurdish, Kiswahili, Spanish, Hmong, and many more.

The organization also partners with resettlement agencies and it has recently launched an app in partnership with the UN to connect newcomers to resources in "real life." This app uses Google Maps to direct newcomers to agencies and resources that may of use. When I asked the employee what his thoughts were about being online but still needing to depend on physical, "real life" help, he stated:

We're hybrid. [The website] is the center where you can come to if you need information for jobs and career. But if you also need where you can actually go, and get help with a resume, we provide you that platform as well.... [We're the] hybrid between the people that can serve you, and you. And then we have a capacity to serve you in terms of online things- GED, we have a citizenship class that's also translated.... We have all kinds of information like that where people can come to and learn but if they need more, like 'how do I-I wanna move into a house, what do I do?' You can read the information but you can also go into our app in housing and find a place where they can help you ... find an apartment.... So it's just kind of providing the overall, the umbrella of things.

The RCO is a hybrid of the physical and the virtual. Thus, although the website provides a general overview of American life, it is nonetheless limited to the reader's geographical area. This is in contrast to social media, which often defies geographical constraints; people living far away from each other can communicate and engage outside of the realm of geography. Social media becomes a place of its own, while the RCO is a hybrid physical-virtual place.

\section{The RCO as Non-Rhizomatic}

The "Voices" section of the website is useful in demonstrating the RCO's focus on a “non-rhizomatic," one-way shift of identity. In our interview, the RCO employee mentioned that the Voices section is a place for newcomers to hear each other's stories and heal. He stated, 
We're hoping through seeing other's stories or other people sharing stories, more and more refugees will be able to ... say, let me share my story. Let me share my journey.... That's the goal. We're trying to encourage that, that way they can share their stories to allow that healing.

This section of the website is constantly expanding with new articles published quite often. A quick search reveals practical articles with titles such as "The Things I Thought About During my Bank Search" (published on Dec $\left.5^{\text {th }} 2018\right)$, "Paying for College" (October $\left.5^{\text {th }} 2018\right)$, or "Moving into a New House" (October 14 $\left.4^{\text {th }}, 2018\right)$. Other articles veer more toward advice with titles such as, "Solutions for Missing Traditional Food" (October 12 $\left.2^{\text {th }}, 2018\right)$, "What Should Refugees in America Do When They Arrive?" (October $\left.2^{\text {nd }}, 2018\right)$, or “Child Obesity: A Refugee Shares Tips on What Needs to Be Done to Avoid It" (July 22 $\left.{ }^{\text {nd }}, 2018\right)$. The majority of articles seem to be experience-based: "Coming to America as A Transgender Man" (October $\left.24^{\text {th }}\right)$, "Why I Grew Up Not Talking Politics in my Home Country" (July 20"th 2018), or "This 15-year-old Former Refugee Describes What America Really is for Newcomers.” Articles are generally quite short and are limited to 500 words. Though varied and diverse, all articles (that I have seen, at least) seek to uplift the readers and most laud America for its inclusiveness and freedom. According to the RCO employee I interviewed, the Voices section is An open platform. Anybody can submit an article and then we try to not, cause we know English is their second language, therefore the articles might not be pure research based. It's more like stories. And so, we try to keep in their language. So it might have- we try to correct grammatical errors, but the flow of how it's written, it's completely entirely to them. You know, we just try to publish it as it is. So it's open forum.

And then we always try to say hey, try to keep it very easy language, just sharing your story, overall. Use I a lot, because we want to hear from you. This is not a college paper. We want you to just kind of share the story the way you would share it if you were being interviewed or just sharing with your friends. So it's very laid-back. And this is 
where...people can come here and read the other experiences of refugees and immigrants. It's almost we having refugees teaching other refugees.

Perhaps this "easy language" and 500-word limit explains why a few of my informants mentioned that they felt the articles were lacking in speaking about the trauma of having to flee, relocating, adapting to the United States, and missing home. Commenting on a Voices article, Hamid mentioned,

What I sacrificed, what I went through, I didn't see it here. I didn't read someone he said I woke up at three am crying in my bed when I remember what I lost back home. Or I miss my family or I miss my job or my friends or my country. I didn't see that. 'My Goal In 2018 Is to Write a Book' [referring to a Voices article title]. Now that means he can pay his bills, his kids they're doing fabulously at school, no one ill, no one have trauma, and now he have free time to write a book? Seriously? I'm a refugee and my wife work too and we didn't have enough time to take our kids maybe even to park. This is not beautiful life as they present it here on this website.

He highlights here that he perceives a lack of conversation around the difficulties of being a resettled refugee in America: living far away from loved ones, missing one's home or one's job, having to work hard to make ends meet, the list goes on. Rather, one encounters articles such as "My Journey to America: The best thing that has happened to me" (Sedrick H. 2017), in which the focus of the story centers around coming to America. It uplifts and brings hope about starting a new life from resettlement onwards. Referring to this article, Khalil stated: I just, I didn't see the point. Why is it the best thing ever happened to him... he keeps saying it, he says it in the beginning, he said it at the end, it's the best thing- thank god. But why? He didn't explain why. He talked about the pluses, Tanzania, then coming here, adapting.... and then suddenly, it's the best thing. Great! What makes things great, you know? What makes it the best? I don't know... It's more like a Facebook status than it is an article. [chuckle] because you don't explain everything in a Facebook status, you don't have to. 
As a "Facebook status", this article does not speak to the traumas, difficulties, and realities of negotiating one's feelings of being both "here" or "there," or neither "here" nor "there." Thus, the Voices program provides a significant example of the RCO's focus on "transplanting" one's roots to the United States, rather than encouraging a rhizomatic conception of self.

However, the RCO employee mentioned that newcomers are not forthcoming with their stories of trauma. Thus, the lack of nuanced storytelling is perhaps due to the deeply personal nature of retelling one's life. The RCO employee mentioned,

It's very difficult to get refugees to write about their personal life stories, and that's one of the reasons that we try to compensate them. So that way we can pay for their time.... But it's always been a very difficult thing, and that's because they're still not over that yet.... We've had some that share like a little more in depth about war, going through all these things. And the trauma. But yeah, it's always difficult to get more and more to share their stories.

It's going to be on the website and [people are] afraid to be seen or found- whatever.... We're very flexible. We provide a platform where you can... submit the story and choose whether you want your name to be in the title of the story or not. So it's completely trying to serve these individuals and say, 'Hey, you can still write a story.' ...Like somebody who belongs in the LGBTQI community...maybe their environment back home is not even supportive of that, so they don't know how to share that kind of story....The Voices is a great platform where somebody can come in and share their story without having their name revealed and share their experience. We've had a couple of that.

Although the Voices section may be quite "America-centered" and evokes more of a "transplanting" than a rhizomatic discourse, this might in part be an unintended consequence of having such a public platform. The RCO encourages people to write about their lives and to learn 
and heal from others' experiences. Yet, the Voices' 500-word limit and the deeply personal nature of sharing one's life and traumas with strangers online may keep authors from writing more rhizomatic pieces. Perhaps, then, keeping a one-way focus on life here and writing about one's hopes and gratitude for living in the United States is much easier to do.

\section{The RCO as a Place to Consider "Being American"}

Of particular importance to my discussion is the "Life in America" tab, through which one encounters the "American culture" section. The section contains numerous subsections to explore, such as: "Culture Shock," "American Values," "Talking and Communicating," and "American Behavior." The "Voices" section of the website, in which immigrants and refugees are invited to write about various experiences, also highlights important messages concerning the "social processes" of citizenship_-something I will explore in depth in the following chapter. For the purposes of my project, I have focused mainly on the "American Values" and "American Behavior" sections, as well as on "Voices" articles, when conducting my discourse analysis and interviews.

In interviews, the focus remained on these sections as well. I asked 11 of the 21 participants in this project to look at these sections and this was determined by the flow of the conversation, the time we had to speak, and whether it seemed natural to veer the conversation to this particular topic. With these 11 participants, we discussed what they liked/disliked about the material, what they thought was useful/not useful, and what they thought of the overall information presented. Interestingly, out of the 11 persons I had explicitly brought up the website to, approximately three had heard of the Refugee Center Online by virtue of their employment with a Portland resettlement agency. These three were also the most critical of the material. 


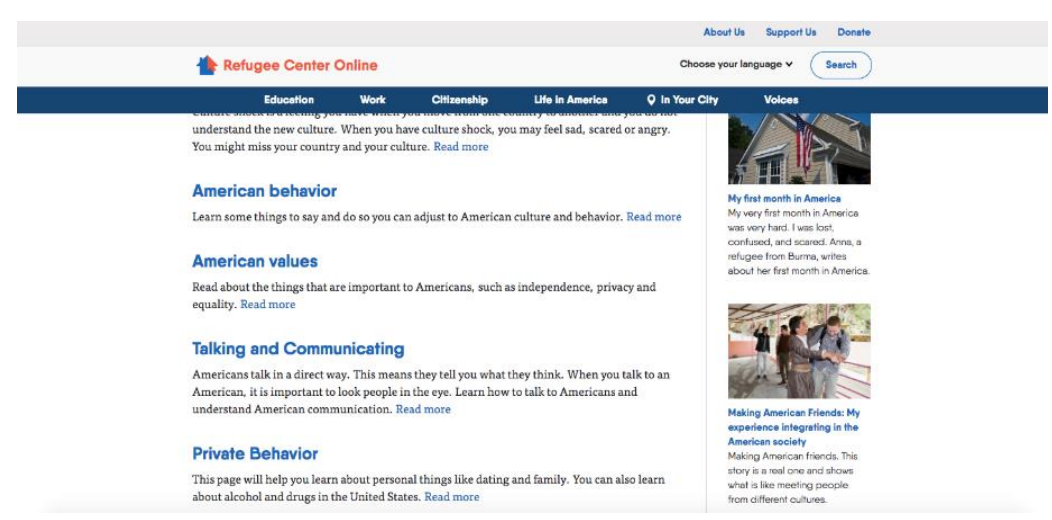

The "American Culture" section of the website

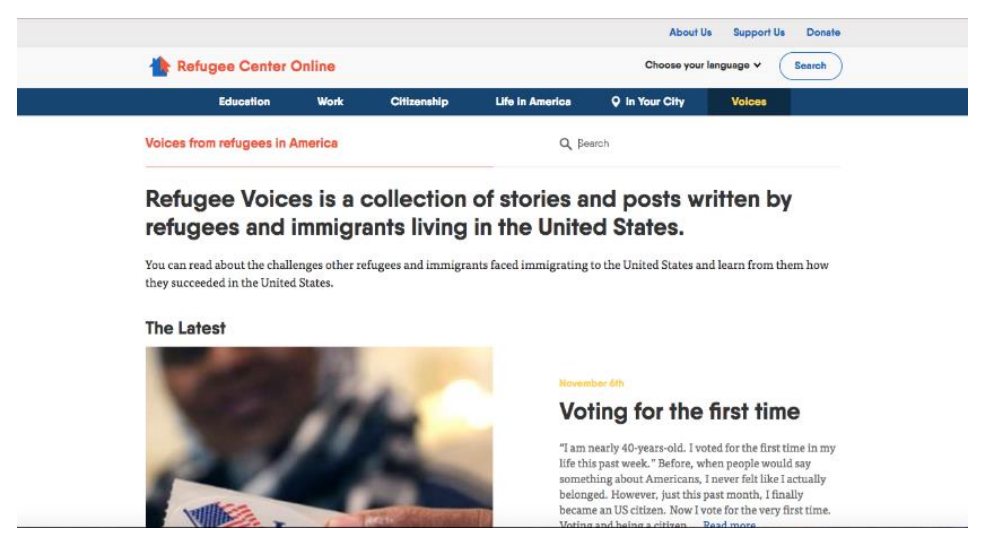

A screenshot of the "Voices" page taken on November 9, 2018.

The "American culture" section of the website presents generic information applicable to a wide, culturally diverse audience. For instance, "American Values" outlines nine American "values": independence, privacy, directness, equality, informality, competition, time and efficiency, work ethic, and consumerism. Like Facebook, the RCO becomes a place-albeit one geographically limited to the United States. It is a hybrid physical-virtual place: an American cultural "center" for people to come into, visit, and get information from. It becomes, in other words, a "cultural resource center."

Many, if not most, informants were enthusiastic about the material presented on the website. Ali asked me if I would send him the URL for the website, as did another informant originally from Myanmar, Sharifah. Both stated they would share this website with their friends 
and family. Many others stated they wished they had seen the website when they had just arrived. Upon reading some "Voices" articles, Eva noted that even though articles may be missing aspects about the difficulties of being a refugee in America and resettling, seeing people's stories of happy, comfortable lives gives hope: "It's so important to hold on to that hope. I feel like that's what is the thing that gets me through anything in life, is the hope...and so, seeing other stories and like, oh yeah...it's inspiring." Esperance, after reading a person's story of opening their own business, stated that reading this reinforces her belief that America is a land of opportunity and that she can do anything here.

Upon showing people the "American Values" article, I found that many already espoused the values - particularly those surrounding open-mindedness, equality, and independence. The RCO provides a place in which informants can explicitly consider "being American." Here, they can reaffirm themselves and what they already consider to be American values. Mina, a young Syrian woman who came as an asylum seeker five years before our interview, mentioned:

I actually like the culture here. I feel like I belong. I feel like I share the values and... of America and American people.... Like, independence and equality between men and women. And, just like the right to vote or elect the party. I share ideas with or share values with. And to...just being free, having the freedom to voice my ideas and thoughts without being afraid for my safety.... And also over there, people judge a lot. Like here, I like it how I can just live my life however I want it and without being judged. And like wear whatever clothes I wanna wear without being judged. I just like it. I can be myself. Combined with these tenets, I frequently heard informants appreciate American values of "selfsufficiency," "staying busy," and "entrepreneurship." For instance, the Kurdish couple Sera and Araz mentioned that owning their own business here is a goal of theirs. They said,

Sera: Because we are not very young to start from the beginning.... So it's good to think about having your business, something like [that]. 
Araz: We are used to [using] our minds to make money...yeah, not to do physical effort to make money.... You have to live smarter than working harder here in America. Araz's last point especially highlights the value placed on entrepreneurship and self-sufficiency in the US. The notion of living and working smarter by using the mind, rather than working harder doing physical labor is seen as a goal to achieve. Indeed, Ong drives the point when she writes, "Increasingly, citizenship is defined as the civic duty of the individual to reduce his or her burden on society, and instead to build up his or her own human capital —in other words, to 'be an entrepreneur of her/himself" $(2003,10)$. To be strategic, disciplined, shrewd, and independent are traits to aspire to. Araz and Sera themselves certainly value self-sufficiency, as evinced in their desire to build up their own small business and become successful businesspeople. As a place to explicitly consider "being American," the article allows Mina, Araz, and Sera to reaffirm values they had already attributed as American.

As Cannedy writes, resettlement agencies work to form refugees into ideal citizens, demonstrating that "citizens are not born, they are made" (Cruikshank 1999, 3). To be an ideal citizen "is tied to wealth accumulation and self-reliance" (Cannedy 2011, 29). It is to be selfsufficient and entrepreneurial. That is, it is to be "someone who demonstrates responsibility and a strong work ethic.... Rejecting this ethos is [therefore] framed as failing the self and society" (Cannedy 2011, 32). Yet, a refugee automatically counters this notion; refugees depend on state benefits and on welfare to survive after resettling. Moreover, they are often "shuffled into lowwage jobs" which generates "a new underclass of Americans" (Cannedy 2011, 33). They thus cannot always be self-sufficient, entrepreneurial ideal citizens.

This idea of being dependent certainly explains why Mai’s family felt so much shame about being refugees: 
“My parents didn't talk about it. Our family didn't talk about it. Until I actually went to law school. They were like, yeah we're refugees. Yeah, we're refugees.... The shame culture of that name, the term refugee is such an ugly term. It's the unwanted, it's the other, it's the foreigner, right. You were abandoned by your own country. You were given an opportunity by this new country, but they don't really want you. You're a pity, they took pity on you. You have to prove yourself, but you're good enough- you're never good enough."

Refugees are pitied and they "depend" on the state the begin anew. They must therefore be "remolded" into acceptable subjects. These discourses centered on the importance of independence and self-sufficiency seem quite present in my informants' minds about what it means to be American - as we see in Araz's and Mai's quotes. As I will explore later, the RCO as an online space in which people can explicitly consider being American and which reaffirms American values has important implications for the crafting of people into familiar, American subjects.

\section{$\underline{\text { Conclusion }}$}

In this chapter, I introduced two online platforms: social media—mainly Facebook—and the Refugee Center Online. I have demonstrated that my participants use social media to emphasize, reaffirm, and build upon their feelings of hybridity. In contrast, the RCO is a website dedicated to transforming refugees and other newcomers into Americans; in other words, it focuses on having newcomers "transplant" their roots from "there" to "here."

Throughout the chapter, I have invoked the notion of the online resources as place. Social media as "place" allows participants to remain connected to their countries and cultures of origin. It further allows them to be co-present and feel they are "hanging out" with friends and family. Moreover, social media as a place allows people to reaffirm their rhizomatic selfconceptions, where people can unite different aspects and social networks of themselves into one 
space. I have also given examples as to how informants use social media to feel "real" and "themselves" again, particularly directly after relocating to the United States. Social media can thus provide a kind of comforting meta- friendship that is always present. Lastly, I highlighted that social media plays a meaningful role in the performance of kin- and friend- work; where instantaneous communication was impossible before, social media platforms allow for rapid, easy communication. It is like an easily accessible space for people to meet up in. However, a few informants mentioned they could not or did not want to maintain strong kin- and friendwork. While this decline may be due to my informants becoming more hybridized and hyphenated-American, my analysis has demonstrated that are alternative explanations.

The RCO is akin to a place as well—albeit one of a different kind than social media. I have highlighted that the website arose from a cultural orientation framework, one designed to teach newcomers about being American. The website emphasizes American values of selfactualization, entrepreneurship, and self-reliance, and becomes a space. In this space, many of my informants explicitly considered what it is to be "American," and they could reaffirm their own values and what they already believed are American values. The RCO focuses on a neoliberal concept of personhood disassociated from social networks, thereby obscuring a rhizomatic sense of being and belonging both "here" and "there." Introducing a comparison between the two online resources provides insights into how people experience belonging and how they create, maintain, and enact rhizomatic self-conceptions. In the following chapter, I explore how participants use both online resources to learn how to "belong" in the United States. 


\section{Chapter III. Becoming American Online}

Having explored how informants use social media platforms — mainly Facebook—and having introduced the Refugee Center Online and how informants perceive it, I now investigate how these online platforms might shape informants' feelings of being American. I first question how informants use Facebook in this regard, and I then turn to a discourse analysis of the RCO's material to highlight its underlying assumptions about being American and what they can mean for newcomers.

\section{$\underline{\text { Facebook }}$}

Undeniably, questions concerning belonging and being American are quite salient in an online context; informants have demonstrated numerous times how online contexts can expose and reassert a sense of hybridity. Yet, how do people use social media, as well as other communication technologies, to learn about belonging? When I broached the topic with Khalil, he did not think of social media as being particularly helpful for becoming American:

I mean, how can it help me feel at home? Sure, I'm connected to people, I'm connected to certain... businesses here, companies, pages and stuff. I don't know, maybe I just never thought about it.

Yet, it is perhaps its subtlety that makes social media a critical influence on people's feelings of belonging. As Khalil himself mentioned earlier, he utilizes social media to know more about what is trendy, what is happening, and what people are interested in: "You look at other peoples' experiences. And, sometimes you learn from it...like you know what's going on.” Indeed, Khalil mentioned that he has about 400-500 Facebook friends, many of whom are Americans or hyphenated-American. And, if we accept Geertz's notion of culture as a “pattern of meanings embodied in symbols, a system of inherited conceptions expressed in symbolic forms by means of which men communicate, perpetuate, and develop their knowledge about and their attitudes 
toward life" $(1973,89)$, social media, by virtue of being constituted by language, images —in short, symbols - necessarily imparts cultural information. In particular, these symbols can be culture as food, description of family life, or politics. Of course, using social media does not impart any singular, bounded "American culture," nor are people only exposed to American culture online; quite the opposite, in fact, because people use Facebook to connect with people all over the world and are thus exposed to ideas from many different cultures and points of view. They "swim" in multiple ways of seeing the world. Using social media thus allows for a multifaceted, plural reaffirmation of oneself online. Further, we cannot cleanly delineate, categorize, and define what counts as a cultural symbol, for symbols are nuanced, complex, diverse, and part of a national imagination (Anderson 2006). Yet, simply scrolling through Facebook, looking at what people are doing and how they behave can give people clues into what it means to be American — such as insights into approaches to food, holiday traditions, or political divisions. Like Eva's use of Instagram to be connected to Latvian culture, logging onto Facebook and exploring what is trendy or what is acceptable brings people into so-called culture centers, where ideas and symbols related to the national imagination (Anderson 2006) flourish.

This notion of social media as a cultural center for learning about being American is highlighted by many informants mentioning they go to social media for news. Upon asking Hamid if social media affects his feelings of being American, he stated,

Of course. Because all the news I saw, it's on Facebook because I follow the news agencies on Facebook. And I saw what they post and I saw what the American people say, the opinion. And I watch, how the American people deal. And I can learn from all those things.... For example, when what's happened with DACA.... I follow what the President Trump say or how the people they deal, what their reaction, why they have this reaction, what the DACA mean....All these things I learn from Facebook. 
Following the goings-on of American politics through Facebook allows Hamid to feel more deeply embedded in America. He already spends " 24 hours a day" on Facebook, according to him; he goes on social media as soon as he wakes up in the morning and throughout the day. Exploring how people broadly classified as American write about, react to, and think about politics and current events is thus incorporated into Hamid's daily routine.

Building national identity through news and print media has a long history, as Benedict Anderson demonstrates in Imagined Communities. He writes that the emergence of "printcapitalism" connected people through linguistic unification and emerging "print languages." This in turn allowed for "unified fields of exchange" that eventually developed into national consciousnesses: "Fellow-readers, to whom [people] were connected through print, formed, in their secular, particular, visible invisibility, the embryo of the nationally imagined community" (Anderson 2006, 44). Now that newspapers have gone online, and thus so have the communities they create, print-capitalism has gained a digital dimension. Like print-capitalism, then, Facebook serves as a way for Hamid to connect to Americans and to feel a part of the national community. And, like Khalil's earlier statement highlighted, learning to belong is often slow, gradual, and subtle. Sometimes we do not realize it is occurring, like Khalil's example hints at, and sometimes it is an obvious, directed effort to incorporate oneself into the national imagination, as Hamid does with American news outputs.

Many informants mentioned the importance of the Oregon Iraqi Facebook group in their lives. There is a closed, private group for Iraqis living in Oregon to discuss issues and ask questions and an open group for disseminating information about the Iraqi Society of Oregon's events. Of particular interest is the former, which consists of almost 900 members living in Oregon. According to Hamid, one of the administrators of the group, it is useful for educating 
people, giving information about benefits, and dispensing pertinent news to the community. He stated, "Any service we have, anything, we try to publish like party, like section 8, or like a new jobs or something." When we looked through the page together, Hamid showed me posts such as someone announcing a party, advertising a (new) business, or an individual looking for help to enroll their child in a sports team. People introduce themselves, and the administrators post information about debit cards, for instance, because "Many people they don't deal with the debit card before" coming to the US. There are posts for job openings, apartment rental availabilities, workshops, classes, and much more.

The "placeness" of social media (Horst and Miller 2012) is significant in two ways: the group becomes a sort of "cultural resource center" for gathering information and sharing news relating to life in America, but it is also limited to people in Oregon. So, the group is itself a "place" for people to come together, while also being dependent on members' physical existence in Oregon, because people in the group interact about happenings which physically take place in Oregon. Further, the Facebook group manifests an Iraqis in Oregon catnet, in which the persons subscribed to the group broadly share the attribute of being (mostly Iraqi) immigrants seeking support and help and come together to create a network (Brubaker and Cooper 2000, 20). Members come together to share information, learn more about how to navigate the intricacies of banking, accommodation, or find jobs. It thus gives people a voice to air their experiences, their needs, and advice and feel they are surrounded with people who have undergone similar experiences.

Certainly, many (former) Iraqi refugees mentioned that they like to help through this Facebook page. Khalil stated,

It's your people, they come here, they know nothing. You know when you come to a new country and all of a sudden, you're forced to leave your home country and you come here 
and it's like you're lost. You're thrown in this place and you don't know what's going on, so...I like to help people, I like to, you know-people who need advice in terms of school, in terms of career, in terms of that kind of stuff. I do that a lot.

Khalil often connects with people through the page and uses his experience and knowledge to help "his people" navigate and understand the system; in other words, he engages in a kind of social work through which he can build social capital by spending time on the website to provide information to newcomers. And while immigrant communities have helped one another long before the ubiquity of social media or digital technologies, the placeness of social media strengthens these community ties, enabling people to reach out and help or be helped from the convenience of their digital devices. Furthermore, it is not just a place to visit and gather with others synchronously, but also an asynchronous resource in which one can scroll back through prior threads and conversations to ascertain answers to previously posed problems or questions. It is noteworthy that most of the content is in Arabic and that most members are Iraqi. Thus, while some members are not Iraqi, this page is quite culture-specific providing help, advice, and information from a particular cultural lens. As a caveat, the page is sub-culture specific as well, because some Iraqi Kurds and other people from the Arab world use the page, although its members appear mostly to be part of the Arab-majority population of Iraq.

A couple informants mentioned that they do not use social media to learn about belonging or being American. Araz, the Kurdish man who arrived three years before our interview, deleted his Facebook page so as to focus on his life here. He will surf his from his wife's Facebook account from to time, but he scarcely utilizes social media. He stated, "So I am no longer with [friends in Kurdistan] and... actually, I don't want to keep this link with Kurdistan because, you know what, if you wanna go with your life here, start a new life, adapt to the new life, so you have to forget about your old life." Araz avoids social media to explicitly negate a 
sense of being "here" and "there"; he feels Facebook distracts him from focusing entirely on his life in the United States. Therefore, one cannot say that social media is a particularly useful means for him to learn about belonging here. Indeed, it is quite the opposite for Araz. Yet, this is not to say that digital technologies have not been important for his experiences in the United States; he spoke fluent English before arriving and did a great amount of research online about life here, such as how to get a driver's license, how to find an apartment, or how to get a Master's degree. Further, he is currently enrolled in an online MBA program through an American university. Although social media has perhaps not had a traceable impact on his feelings of belonging and of learning what it means to be American, the wider internet has. Of course, this is a question for future research. Nonetheless, the examples I have portrayed demonstrate the various ways, imperceptible and not, that social media affects current and former refugees' understanding of how to conduct themselves as American. The private group for Iraqi-Americans provides information for others in the catnet. The RCO tries to perform this same function for wider refugee and immigrant communities in the United States.

\section{The RCO as a Cultural Resource Center}

Like the Iraqis in Oregon Facebook group, the RCO is a cultural resource center-albeit one of a different kind. This is one founded by American women, who have crafted information about life in America in collaboration with a refugee advisory council and other refugees. This material is designed to be an informal cultural orientation, through which refugees and immigrants can learn what it means to be American. Ong reasons that the "social process" of citizenship occurs almost imperceptibly through the "political effects of institutional processes that are deeply imbued with sociocultural values" $(2003,77)$. She argues that these institutional 
processes do not occur through an "overarching state apparatus," (see also Foucault 2007, 108109; Rose et al., 2006, 101) but rather via many different nodes and networks "through which various authorities, nonprofit agencies, programs, and experts translate democratic goals in relation to target populations" (Ong 2003, 78). In her work, she points to the medical field as a prominent area in which these forms of "governmentality" occur. Following Foucault, Ong perceptibly demonstrates that "Social work is inscribed within a larger social function that has been taking on new dimensions for centuries, the function of surveillance-and-correction: to observe individuals and to redress them, in the two meanings of the word, alternately as punishment and as pedagogy" (Foucault 1999, 92). Cultural orientation undoubtedly plays a prominent role in this dynamic of "surveillance-and-correction."

The $\mathrm{RCO}$ - a platform dedicated to providing informal cultural orientation information to newcomers - provides an intriguing viewpoint from which to analyze citizenship construction. We can feasibly consider the website a "contact zone" (see Heinemann 2017) — a "social space where cultures meet, clash and grapple with each other, often in contexts of highly asymmetrical relations of power" (Pratt 1991, 34). Although it resides outside of the US Resettlement system requirements, I highlight that the website nonetheless transports hegemonic, nationalist discourse inherent in the "social process" (Ong 2003) of crafting neoliberal "ideal citizens" (Cannedy 2011).

In her research on language classes taught to refugees and immigrants in Austria and Germany, Heinemann raises Ong's social process of citizenship (2003) and Cannedy's creation of the ideal citizen (2011) in her discussion of the "subject formation" that underlies these classes. She writes that they are part of civilizing efforts that reify the hegemonic, nationalist narratives upholding "Western" values as dominant. These efforts work to normalize refugee and 
immigrant others into good, normal citizens (Heinemann 2017, 185). And yet, Heinemann highlights that the values presented are imagined: "there is no agreement about which values exactly should be counted as national values, but there is a sort of consensus about imagined national values" (Heinemann 2017, 178). In other words, a delineated, distinct value-system is an imagined phenomenon foundational to nation-state building projects (see also Anderson 2006): in reality, the plurality of people who make up the German/Austrian nation-states repudiates the notion that there are delineated "values" that constitute a universal German/ Austrian identity.

This refutation raises Wimmer and Glick Schiller's argument that (forced) immigration in the nation-state building project destroys four ideals; in particular, it destroys "the isomorphism between people and nation," wherein nation-states are forced to reckon with their histories and politics of forced assimilation or forced displacement $(2002,309)$. This refiguring represents a "renewed challenge to the nation-building project and points to the fragility of its achievements-especially in places where the nation has never been imagined as plural" (Wimmer and Glick Schiller 2002, 310). However, as both Wimmer and Glick Schiller (2002) and Malkki’s (1995) suggest, people have always moved, migrated, and circulated; place, culture, or country has never not been plural, diverse, or unproblematic. In reality, "The very concept of 'migration' emerged from the growth of national bureaucracies" (Hein 1993, 47). By extension, values have always been plural and it seems quite erroneous to believe that a distinct, delineated value-system accurately represents the diversity of people's worldviews, attitudes, and identities in the nation-state.

Undeniably, unambiguously presented national values are "imagined," as is certainly the case for the RCO's content. A few people highlight the RCO's "imagined" nature: Eva, the 
young woman from Latvia who feels Latvian-Russian-American, stated, "It's hard to generalize the whole United States of America and like, you as a person meet so many other people [who] like don't subscribe to American culture... There's like people in the South who are different." Obviously, the United States is such a large territory with vastly differing behaviors and local histories, and Eva alludes here to the deep-seated belief in America as a "melting pot," a nation made of immigrants. The United States has historically been defined by its plurality, so Eva's statement questions how exactly we might generalize values for the entirety of the United States.

Furthermore, participants' varied reactions to the RCO's definition of American values also highlights how they are "imagined." Take the website's stance on the US value of “directness," for instance: they write, "Americans are often very direct. This means they often tell you what they think and they will be assertive about what they want....Americans are not trying to be rude - they are just being direct" (RCO 2018d). And yet, a few participants contested this assertion. Eva mentioned, "I would not say that Americans are very direct. Talk to some Russian people..." Read: Russians are much more direct than Americans and the latter are not so direct after all. On the other hand, Ibrahim, the elder from Iraq felt differently, saying that American "directness" can often go so far as to be rude, while not being quite so to the point at all. He stated, "The Americans are very linear [direct] but then at a certain point, you find Americans are saying nothing after a few sentences." The juxtaposition of these responses helps highlight that this value is "imagined" and is not an ingrained, concrete, unambiguous given that everyone can agree with. We cannot know what Eva and Ibrahim experienced in terms of directness, although the issue is clearly that there is a range of "American" behavior and a range in how refugees and former refugees interpret it. 
The "American behavior" article was similarly questioned by a couple of my informants. It presents ten "tips" for adjusting to behaviors common in the United States: "say 'please;' say 'thank you'; say 'sorry'; cover your mouth when you burp or cough; say 'hello' when you meet new people; don't shake hands if you don't feel comfortable; stand at least a foot away when you are talking to someone new; look people in the eye when you are talking to them; stand in line; hold the door open for people" (RCO 2018e).

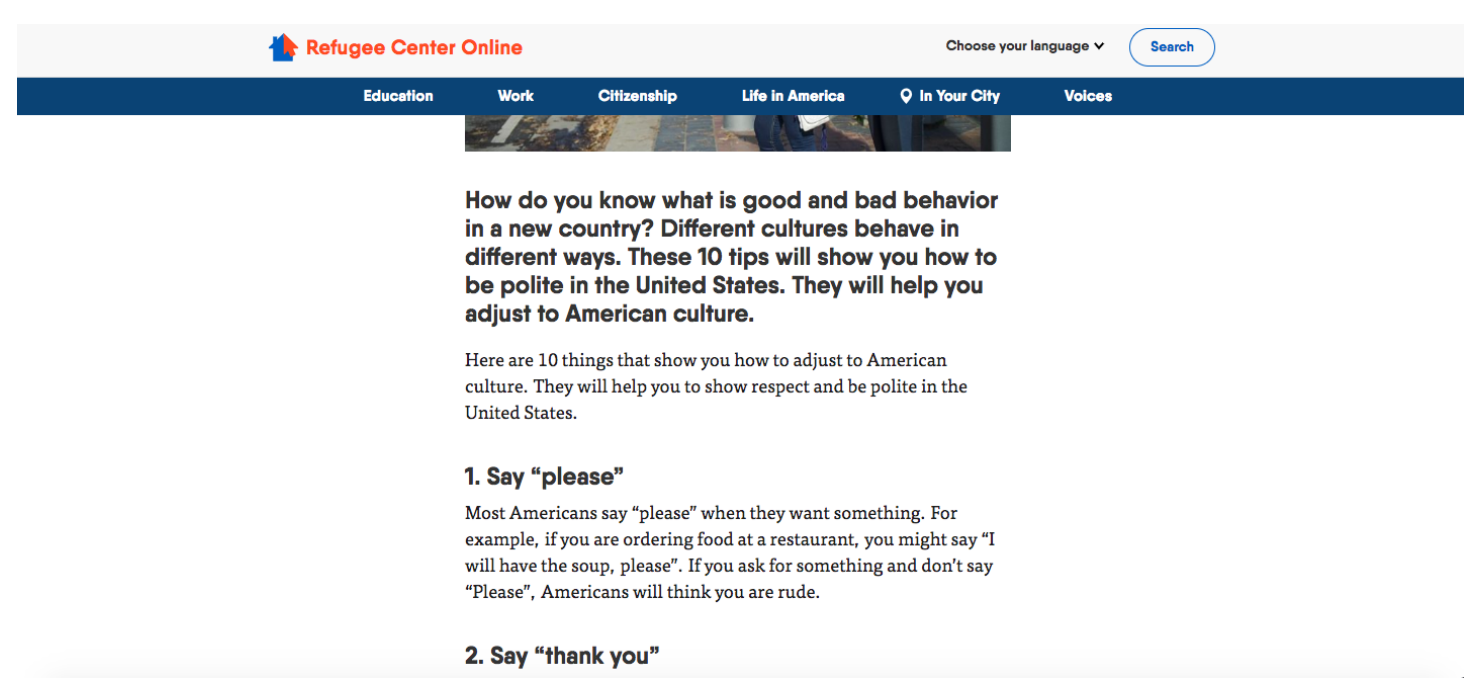

“Ten Tips” (See RCO 2018d)

The three people I mentioned earlier who were most critical of the material were offended by this piece. Eva mentioned, “It's treating people like they don't know how to function in society...also, like... look people into the eyes when you're talking to them...like that's...like, I don't want to do that or that's not how I was raised." Ibrahim stated,

It's superficial, it's very arrogant and superior. Say hello...OK, by the way, Americans don't say hello because you'll go into an area, you'll go into your tunnel, not acknowledging the presence of people. In our culture, when you go into a space, you have to acknowledge the presence of people, even if you are not going to interact with them directly.

In regards to the part about covering one's mouth when coughing or burping, he further stated, 
This should go under health, this is not American culture. You see, this is how I would put it if I'm the cultural consultant for them. Cover your mouth, because some countries don't care about infectious disease. This should go under health, how to prevent diseases and then that's when you tell people, you should cover [your mouth].

Eva and Ibrahim feel the simplistic wording as reinforces a difference between Americans and newly arrived immigrants and refugees, effectively othering them. The two informants feel this discourse is blatant "correction" of "others" behaviors (Ong 2003). This is especially inflammatory when Americans do not even behave as the RCO presents, like Ibrahim points out. Further, Ibrahim finds that if the RCO were to place the information about covering one's mouth in a section on health, it would appear less as a patronizing redress; it would be less about telling someone what they should know about politeness, and more about a focus on avoiding the spread of disease. Instead, they find that the RCO engages in "civilizing efforts," to mold refugee and immigrant - non-American-behaviors into accepted, normative, and "civilized" conduct. They find that the simplified language and basic tips hoard refugees and immigrants into a bounded group of people who needs reeducation, rather than people from vastly different backgrounds who have become categorized as refugees and immigrants for a time (Malkki 1995; see also Brubaker 2000).

However, Eva's and Ibrahim's opposition to the material in both articles begs the question of whether they have been in the United States long enough that they have internalized these rules of politeness. Furthermore, even though values may be imagined, they can nonetheless be real. As Khalil mentioned, these rules are not unique to American culture; Eva and Ibrahim mentioned they grew up with similar norms. These values have thus been known to them for a while. Would someone who comes from a place where covering one's mouth is not common want to explicitly know this is impolite in the US? 
The key question, then, is whether having these ideas addressed explicitly is useful or if it is patronizing and degrading. The RCO employee repeatedly emphasized that the website is designed to give a very broad overview of American culture to people who come from very diverse cultures. According to him, these values are not self-evident to everyone. In fact, he mentioned that refugees and immigrants themselves asked for this information.

Most this website is built almost by refugees and immigrants because the information that's there, they wanted it to be there. They're the ones that said, we would love to have life in America section, where we can have all the different categories: American culture, understanding the society, the culture shock and all those things... this information is coming from immigrants and refugees themselves.

Thus, the employee highlights how there was a demand for explicit explanation of American cultural expectations. Of these expectations, he stated,

We want to educate [newcomers]. 'Here's the American culture,' so that way they know what to expect. That way they don't have a lot of expectations. Like, if I'm a Muslim lady and [in] my culture, I can't shake a hand with a guy, ...then us, the Refugee Center [teach] American culture. [We say] 'Hey... A firm handshake is important in America because that's what they do in the business world.'... So that way, that lady understands like 'OK, if somebody shakes my hand and I'm wearing [a hijab], I don't expect them to know I can't shake hands. I don't expect them to know who I am. I have to explain it to them. I have to educate them.' So, we trying to provide overall, general overview of the American culture, so that way refugees know the expectations. And also know where they fit in.

The people who asked for this information find there are benefits to being perceived as "polite" by members of the dominant culture. One knows what is expected and also knows what to expect from others. This way, newcomers can retain aspects of their culture, such as not shaking someone's hand, while understanding American expectations. Nonetheless, the website focuses on a one-way shift of identity; its emphasis lies in having the newcomers understand American culture, not on sharing newcomers' cultures with Americans. It thus works to provide 
newcomers with the tools to know what is expected of them, in order to become "good," "familiar" Americans.

Although the RCO may present "imagined" values, this does not mean these are not significant in how people conceptualize "American-ness." For instance, when I read the website's presentation of the value of equality, I found the content shallow. The article states, "The idea of equality is an important part of US culture.... [although] Some people in the United States do not always treat all citizens equally." And, "Today more and more people realize the American Dream is not true. Many people who work very hard do not have very much money. Often people who come from privileged backgrounds have an easier time moving up in the world" (RCO 2018d). Although the content highlights the nuances between the ideal of equality and the ways in which it falters, the content nonetheless glosses over tensions; for instance, it makes no mention of the Black Lives Matter movement that has arisen over racial inequalities, nor does it specify any statistics about the wage gap between men and women. While it states that "Americans have a right to representation by a lawyer" (2018d), it does not highlight that the quality of representation is inherently class-based. The website only briefly mentions that "It is useful to know that there may still be invisible hierarchies among people. These tend to be based more on individual success: for example, someone's job, wealth, or education" (RCO 2018d). I balked at the lack of nuance surrounding the idea of equality in America today.

However, when I asked the RCO employee whether they felt the values the RCO presents are actually enacted, they stated,

It's kinda interesting. My perspective will be from the third-world perspective, rather than an American person. An American person might say well we need to do better. Because there is many injustices that are taking place. But the fact that you even have it, it's a tremendous thing for me, because I never had it in the first place. So, I think for me, 
coming from a third-world perspective to be able to say, hey, you have the right to remain silent. All those little things. For me, I value that. ... You can still do that. You still going to be judged wrongly but still the process was there. It's just that people are abusing how-the process is there and they're going by it. People are just being people, and through politics, through biases...they're just poking holes in it. But still, the system. The theory is there. And it's just so different for a person who's never had it before.

Here, the RCO employee shows that the theory and idea of equality is valuable, even if equality itself is not always practiced in the US. Therefore, even though the value may be "imagined," it tethers the employee to a sense of "American-ness" because they can understand the ideals that underpin the national imaginary. Having these values spelled out then clearly delineates an easily digestible "American culture." Thus, having values like these to equate to American culture, (whether they are enacted or not) allows for a greater sense of belonging.

Many participants were not offended by the content, understanding that this was written for a wide audience. Mina, the young Syrian woman, noted the following when I told her some people were offended: "I mean they also have to understand, like, this was not just like written for them or their country. That was written for a lot of people from all different... all over the world. Maybe ... your country does that, but maybe like other countries do not do that. And this was not just written for Syria or Iraq people." Many agreed with what was stated and mentioned that they had wished they had read this when they had first arrived. They also mentioned they would like to show their friends and other newcomers they meet.

Perhaps this enthusiasm is due to the way in which the information is synthesized into bite sized pieces. These bite-sized pieces simplify integration and allow people to appear more "normal" and "recognizable" despite being "others," thereby increasing their sense of being accepted. Heinemann writes, "As colonialism produced mimic men... the integration and value courses likewise generate subjects that want to follow the rules and norms of the society that 
gave them refuge; a society they want to belong to" $(2017,191)$. The RCO allows newcomers to consciously learn the behavioral codes of the society they want to belong to. Although these ideas may not always be enacted in practice and some are "imagined," understanding these core cultural notions helps people feel like they belong, like the employee highlights above regarding the value of equality.

Reflections on the RCO_ "Are We Going to... Build Something Mutual?"

There is precious little on the website to suggest a rhizomatic interchange between life "here" and "there." Instead, we find a discourse encouraging newcomers to amend behaviors to fit American culture. Ibrahim made an important point after reading through the website:

It's just that again, when most people interact - even if I am kind and I'm accepting you - but am I willing to exchange cultural values, or is it me guiding you into my culture? Assimilating you or we are going to integrate, to build something mutual? If we approach migration with a mentality to share cultural viewpoints, rather than place the onus onto newcomers to adapt to a perceived uniform American culture, we demonstrate deeper respect for people's diverse cultural values, life experiences, and worldviews. We can thus move away from a latent nationalist approach. Undoubtedly, it is not the RCO's intention to disrespect refugees and immigrants — on the contrary, the creators repeatedly emphasize their support of refugees and immigrants. They make a point to show that refugees bring great things to the communities they settle in and there are myriad articles throughout the website that honor refugees and the benefits of including newcomers in our communities.

And yet, we have to wonder, how much of the website's discourse is about sharing cultural values, rather than re-molding and re-making people? Because it is true that "members 
of the dominant society perceive migrants and refugees as subjects must be normalized. What is described as 'integration' is nothing other than a way to produce normalized subjects” (Heinemann 2017, 186). Hamid's point is certainly salient here:

I think here- they teach refugees how to be American, but I didn't see anything to teach American people how to deal with refugees. Because you need to have a balance. You cannot ask refugees to be an American without asking the American people how to deal with refugee to make them feel this is their country. You need to have a balance... This is the American side, what about the refugee side?"

Perhaps the website could benefit from having articles written from newcomers' points of view. Instead of having the "ten tips" on American culture, the page could be replaced by multiple pages written from different points of view: for instance, Ethiopian, Iraqi, and Guatemalan newcomers could each write about some aspects of American life that struck them, how it has affected their lives, and whether they do things differently. The cultural specificity would provide depth that the current content does not have. It would furthermore enable greater rhizomatic interchange. Or, perhaps the website could interview some newcomers and post the transcripts on the website. This would enable newcomers to share their stories in depth, and stay anonymous, if that is their wish. Both of these suggestions would allow newcomers to teach both Americans and other newcomers, shifting the conversation from a "transplant" focus to a more "rhizomatic" and interactive sharing of cultures. In short, I suggest that if the material were written more by refugees and immigrants with a lens for "building something mutual," this would have a fourfold effect: it would amalgamate newcomers as creators and teachers of pertinent cultural knowledge, add nuance and profundity to the information provided, enable dialogue, and lead to an intercultural (per Ibrahim) melding of cultures. 


\section{Conclusion}

Chapter II introduced social media and the RCO, and people's reactions to them. This chapter delved into how people use the platforms to learn how to belong in the United States. I emphasized that both social media and the RCO are sort of cultural learning centers for people to gather information. Many of my informants go on social media to read news, which in turn gives them a greater sense of belonging. This raises Benedict Anderson's (2006) discussion of printcapitalism's role in promoting belonging to the national community. By reading "American" information on social media, informants augment their feelings of being American. I also introduced the Iraqi in Oregon closed Facebook group; this group is akin to a place that fosters a catnet for Iraqis and other Arabic speaking people who live in Oregon. Here, people come together, share stories, ask questions, and gather information about life in America. This page provides information for the community by the community, and bolsters rhizomatic selfconceptions.

In contrast, the RCO is another kind of cultural resource center, one made for communities of newcomers all over the United States. The RCO is less culturally-specific, and thus, geared toward transplanting one's roots to the US rather than creating a rhizomatic selfunderstanding. The website aims to help culturally diverse individuals understand the basic fundamentals about life in America. As I argue, the values presented are imagined; America is known for its plurality and providing unambiguous American values obscures the "imagined" nature of national communities.

Furthermore, I demonstrate that imagined values are nonetheless real; once adhered to, they provide newcomers with a feeling of being accepted as truly American. Thus, the RCO allows people to learn the behavioral codes in the United States, potentially magnifying their 
feelings of belonging. I finish this chapter by offering some reflections on the website. I provide some of my informants' comments and highlight areas where the website could be ameliorated. In the end, while they differ greatly, the two platforms provide interesting insights into how current and former refugees become American. 


\section{Conclusion}

This thesis examines digital media as platforms for current and former refugees to reaffirm and create themselves and to learn to be American. To think of refugees as "uprooted" with "roots that threaten to wither" (Malkki 1992, 32) obscures nuances of lived experiences. This thesis utilizes Deleuze and Guattari's idea of the rhizome (1987) to rethink current and former refugee experiences. With the rising ubiquity of digital media and digital technologies, increasing numbers of refugees resettle in the United States with smartphones and other technologies. These technologies give current and former refugees opportunities to maintain hybridized self-conceptions and to feel they are both "here" and "there."

Prior to digital technologies, refugees sent letters and called landlines to communicate with family and friends abroad. However, as Mai pointed out to me, no one ever really knew if letters and packages would arrive. Furthermore, landlines were not readily accessible the world over and phone cards were expensive; thus, phone calls to family overseas were never an immediate possibility. Now, smartphones are increasingly accessible and affordable, facilitating communication across vast distances. In this thesis, I have highlighted that having instantaneous connection to friends and family provides a feeling of "ambient virtual co-presence" (Ito and Okabe 2005, 264), allowing informants to keep in touch with past and present connections. This thus provides an increased rhizomatic connection to "here" and "there." Furthermore, digital media allows people to have a "place" in which to "meet" people, to store precious memories such as photos, and to have a location in which to gather information about living in America.

Social media and the RCO perform very different functions. I have highlighted that although social media — especially Facebook — allows informants to reaffirm and craft themselves and keep in touch with widely dispersed connections, the RCO focuses on 
“transplanting" roots and provides information on how to become good Americans. Thus, Facebook is a spontaneous creation of self through performativity, both enabling and reaffirming hybrid self-conceptions. It a place apart from geographical location, enabling people to come together and feel they are both within and outside the US. Meanwhile, the RCO is a service provider focused on the geographical area of the United States. It therefore does not propagate a rhizomatic feeling of belonging. Comparing the two websites enables us to understand the role digital technologies can play in resettlement and the effects they have on (current and former) refugees.

\section{Doing Digital Ethnography}

Social media creates virtual social spaces; this has increasingly led ethnographers to discern how to conduct research in these new social frontiers. My research is a step in this direction; in this thesis, I plot how current and former refugees can use social media to bridge vast distances and keep in touch despite not being physically co-present. This research can presumably extend to other migrants and provides insights into how people construct their selfidentities and self-understandings through digital technologies.

In my interviews, I incorporated websites and social media sites. As such, I engaged in some digital ethnography, in which a portion of my research was grounded in the digital realm. I asked informants to show me through their social media pages and feeds, which enabled me to get a sense of how they used the platforms. Furthermore, incorporating social media into my research enabled me to return to a person's profile even after our interview; the Internet's asynchronicity means I could return and see what someone was up to, what they "like," and how they use social media. 
Following Boellstorff, I treated the "digital not as an object of study, but as a methodological approach, founded in participant observation, for investigating the virtual and its relationship to the actual" (Boellstorff 2012, 40, emphasis in the original). Hence, doing digital ethnography was hugely beneficial for understanding how current and former refugees experience resettlement. My informants' virtual actions reflect feelings of self-identification. Therefore, my research highlights that we cannot separate the virtual from the actual. What is virtual is real, thus what is actual is virtual; the two inform each other, both playing crucial roles in my informants' rhizomatic self-conceptions.

Doing digital ethnography does not reinforce the virtual as "artificial." Quite the opposite: "artifice, the act of crafting, is a quintessentially human endeavor" (Boellstorff 2012, 41). Thus, "people are not one iota more mediated by the rise of digital technologies" (Horst and Miller 2012, 11). That is, sociality is not somehow less natural because it takes place online, nor is not lost (Horst and Miller 2012, 11). It is quite the opposite, in fact: my research highlights that digital technologies enable sociality like never before, whereby people can be both "here" and "there." Incorporating digital ethnography into my research has thus allowed me to acquire a different perspective of people's self-identifications - one that lives online, and has an acute bearing on "real" life.

There is space for much more research in this new social frontier. Future work on digital technologies could use focus groups, engage in social networking sites elicitation as does Uimonen (2012), follow people in online chat groups, or continue Boellstorff's (2015) work studying human life in virtual worlds. 


\section{Future Exploration}

As an Honors thesis, this study is quite preliminary and explorative, and a number of themes have arisen that merit more research. For instance, future research could evaluate ways in which digital technologies could better support hybrid identities. This might focus specifically on helping websites like the RCO craft content that encourages rhizomatic selfhoods. Further, future research might look into whether better access to online information leads to increased feelings

of belonging. This could critically examine assimilation, integration, and assess how to create an intercultural bringing together of American and migrant identities.

Additionally, perhaps comparing how resettled refugees from two different countries use social media could shed light into whether they use social media in distinctly culturally-mediated ways (see Miller 2011 for a similar study in Trinidad). Or, future research could look into how people might feel they are digital citizens of more than one place, and how questions of belonging affect trans-border activism. This would build upon Bernal's work with the Eritrean diaspora (2005), in which Eritreans living abroad use the internet to engage in activism.

Another theme that arose in my work that merits further research is that of kinship and care work. Future research would do well to evaluate how kinship and care work might shift with the rising ubiquity of digital technologies. How are (long-distance) relationships reconceptualized? What does this mean for the nuclear family and for raising children? This research would be shaped by Baldassar's (2016) and Madianou and Miller's (2012a) works. In regards to my specific research project, one could interview non-English speaking resettled refugees to understand how they use social media. Questions could include whether they feel they belong in the US, what their self-understandings resemble, and how social media 
affects this. Furthermore, the RCO employee I spoke to mentioned that the organization is restructuring the current website to become a journey map:

We wanted to be easier, like a journey map from like, first three months in America or first six months, to like, one year. Three years. To five years where you are concerned about becoming a citizen at this point and most of the time if you have children, they're going through the school system and they speak English already, so you gonna have content that's different from the other ones.

The website will change shortly. It is therefore possible that my analysis and findings will no longer be applicable. Returning to the website and examining how and if its discourse has changed would provide rich insights. Further, questioning this time-line and what information is deemed to fit at what stage of integration would be significant. Conducting interviews and focus groups about the journey map structure would furthermore uncover insights as to the benefits and problems it poses.

Lastly, future research should consider the current political, ethical, and privacy issues surrounding Facebook. Only recently has the platform been under fire for illegally collecting data from its users in Belgium (see Newcomb 2018), leaking the information of 8.7 million Facebook users to the voter-profiling company Cambridge Analytica (see Rosenberg et al., 2018), and for surreptitiously tracking every minutiae of people's activities, even when surfing outside of Facebook (see Singer 2018). Perhaps the most well-known example is of Russia posting propaganda through fake accounts to "inflame political divisions" before the 2018 midterms (see Price 2018). Future research could question what happens when your meta bestfriend gives away your information and provides you with biased information from fake accounts? Does this affect whether current and former refugees continue using Facebook? How do people negotiate the concept of privacy in this circumstance? What are some alternatives to using Facebook and how viable are they? 
Research into refugees' and migrants' use of social media is undoubtedly timely and significant. It allows for a better understanding of their experiences and, ultimately, of the world in which we live. 


\section{Bibliography}

Anderson, Benedict. 2006. Imagined Communities: Reflections on the Origin and Spread of Nationalism. Revised Edition. New York: Verso.

Arendt, Hannah. 1951. The Origins of Totalitarianism. Schocken Books.

Agamben, Giorgio. 1998. "Biopolitics and the Rights of Man." In Homo Sacer: Sovereign Power and Bare Life, translated by Daniel Heller-Roazen, 126-135. Stanford: Stanford University Press.

Appadurai, Arjun. 1996. Modernity at Large. Minneapolis: University of Minnesota Press.

boyd, danah. 2014. It's Complicated: The Social Lives of Networked Teens. New Haven: Yale University Press.

Baldassar, Loretta. 2016. "Mobilities and Communication Technologies: Transforming Care in Family Life." In Family Life in an Age of Migration and Mobility. Migration, Diasporas, and Citizenship by Kilkey M., Palenga-Mollenbeck, E. (eds), 19-28. Palgrave Macmillan: London.

Bek-Pedersen, Katherine and Edith Montgomery. 2006. "Narratives of the Past and Present: Young Refugees' Construction of a Family Identity in Exile.” Journal of Refugee Studies. 19(1): 94113.

Bernal, Victoria. 2005. “Eritrea On-Line: Diaspora, Cyberspace, and the Public Sphere.” American Ethnologist. 32(4): 660-675.

Bernard, H. Russell. 2011. Research Methods in Anthropology: Qualitative and Quantitative Approaches. Lanham: AltaMira Press.

Boehm, Deborah A. 2012. Intimate Migrations: Gender, Family, and Illegality Among Transnational Mexicans. New York: New York University Press.

Boellstorff, Tom. 2012. "Rethinking Digital Anthropology.” In Digital Anthropology, by Heather Horst and Daniel Miller (eds.), 39-60. London: Bloomsbury.

Boellstorff, Tom. 2015. Coming of Age in Second Life: An Anthropoligist Explores the Virtually Human. Princeton: Princeton University Press.

Broadbent, Stefana. 2012. “Approaches to Personal Communication.” In Digital Anthropology, by Heather Horst and Daniel Miller (eds.), 127-145. London: Bloomsbury.

Brubaker, Rogers. 2002. "Ethnicity Without Groups.” European Journal of Sociology. 43(2): 163189.

Brubaker, Rogers and Frederick Cooper. 2000. "Beyond 'Identity." Theory and Society 29(1): 1-47. 
Bureau of Population, Refugees, and Migration. 2017. "Proposed Refugee Admissions for Fiscal Year 2018: Report to the Congress." US Department of State.

https://www.state.gov/documents/organization/274857.pdf

Bureau of Population, Refugees, and Migration. 2018. "Proposed Refugee Admissions for Fiscal Year 2019: Report to Congress." US Department of State.

https://www.state.gov/j/prm/releases/docsforcongress/286157.htm.

Carens, Joseph. 2013. The Ethics of Immigration. New York: Oxford University Press.

Cannedy, Shay. "Crafting Citizens: Resettlment Agencies and Refugee Incorporation in the US." Practicing Anthropology. (33)4: 29-34.

Cultural Orientation Resource Exchange 2018. https://coresourceexchange.org/about-2/ CORE.

Cruikshank, Barbara. 1999. The Will to Empower: Democratic Citizens and Other Subjects. Ithaca: Cornell University Press.

Deleuze, Gilles, and Felix Guattari. 1987. A Thousand Plateaus: Capitalism and Schizophrenia. Minneapolis: University of Minnesota Press.

Devos, Thierry and Mahzarin R. Banaji. 2005. "American = White?" Journal of Personality and Social Psychology. 88(3): 447- 466.

di Leonardo, Micaela. 1987. "The Female World of Cards and Holidays: Women, Families, and the Work of Kinship.” Signs. 12(3): 440-453.

Foucault, Michel. 1991. "Social Work, Social Control, and Normalization: Roundtable Discussion with Michel Foucault," in Reading Foucault for Social Work, by Adrienne S. Chambon, Allan Irving, and Laura Epstein (eds.) New York City: Columbia University Press.

Foucault, Michel. 2007. Security, Territory, Population: Lectures at the Collège de France, 19771978. Michel Senellart, François Ewald, and Alessandro Fontana (eds.) New York City: Picador/Palgrave Macmillan.

Geertz, Clifford. 1973. The Interpretation of Cultures. New York: Basic Books, Inc.

Gilhooly, Daniel, and Eunbae Lee. 2014. "The Role of Digital Literacy Practices on Refugee Resettlement.” Journal of Adolescent \& Adult Literacy. 57(5): 387-96.

Ginsburg, Faye. 2012. "Disability in the Digital Age." In Digital Anthropology, by Heather Horst and Daniel Miller (eds.), 101-126. London: Bloomsbury.

Hage, Ghassan. 2008. "Roots Will Be With You Always." Originally in The Australian. Published 23 April. Accessed September 12. http://ulcm.org/wlcu-lebanese-heritage/news/roots-andwings/2013/05/30/roots-will-be-with-you-always---by-ghassan-hage 
Harrell-Bond, Barbara and Eftihia Voutira. 1992. "Anthropology and the Study of Refugees." Anthropology Today. 8(4): 6-10.

Hebdige, Dick. 1987. Cut 'n' Mix: Culture, Identity and Caribbean Music. London: Methuen.

Hein, Jeremy. 1993. "Refugees, Immigrants, and the State." Annual Review of Sociology. 19: 42-59.

Heinemann, Alisha M B. 2017. "The Making of 'Good Citizens': German Courses for Migrants and Refugees." Studies In The Education Of Adults. 49(2): 177-195.

Horst, Heather A., and Daniel Miller (eds.). 2012. Digital Anthropology. London: Bloomsbury.

Ilcan, Suzan. 2002. Longing in Belonging: The Cultural Politics of Settlement. Westport: Greenwood Publishing Group.

Ito, Mizuko. and Daisuke Okabe. 2005. “Technosocial Situations: Emergent Structuring of Mobile Email Use', in Personal, Portable, Pedestrian: Mobile Phones in Japanese Life, by Mizuko Ito, Daisuke Okabe, and Misa Matsuda (eds.), 257-76. Cambridge: MIT Press.

Kuwee Kumsa, Martha. 2006. "'No! I'm Not a Refugee!' The Poetics of Be-Longing among Young Oromos in Toronto.” Journal of Refugee Studies. 19(2): 230-255.

Lim, Julian. 2013. "Immigration, Asylum, and Citizenship: A More Holistic Approach.” California Law Review. 101(4): 1013-1077.

Liptak, Adam and Michael D. Shear. 2018. “Trump's Travel Ban is Upheld by Supreme Court.” New York Times. https://www.nytimes.com/2018/06/26/us/politics/supreme-court-trump- travel$\underline{\text { ban.html }}$

Madianou, Mirca and Daniel Miller. 2012a. Migration and New Media: Transnational Families and Polymedia. New York: Routledge.

Madianou, Mirca and Daniel Miller. 2012b. "Polymedia: Towards a New Theory of Digital Media in Interpersonal Communication.” International Journal of Cultural Studies. 16(2): 169-187.

Maghbouleh, Neda. 2017. The Limits of Whiteness: Iranian Americans and the Everyday Politics of Race. Stanford: Stanford University Press.

Malkki, Liisa H. 1992. "National Geographic: The Rooting of Peoples and the Territorialization of National Identity among Scholars and Refugees." Cultural Anthropology 7(1): 24-44.

Malkki, Liisa H. 1995. "Refugees and Exile: From 'Refugee Studies' to the Natural Order of Things." Annual Review of Anthropology 24 (1): 495-523. 
Malkki, Liisa H. 1996. "Speechless Emissaries: Refugees, Humanitarianism, and Dehistoricization." Cultural Anthropology. 11(3): 377-404.

Mikal, Jude P., and Braden Woodfield. 2015. "Refugees, Post-Migration Stress, and Internet Use: A Qualitative Analysis of Intercultural Adjustment and Internet Use Among Iraqi and Sudanese Refugees to the United States." Qualitative Health Research 25(10): 1319-33.

Miller, Daniel. 2011. Tales From Facebook. Cambridge: Polity Press.

Miller, Daniel. 2012a. “Open access, scholarship, and digital anthropology.” HAU: Journal of Ethnographic Theory. 2(1): 385-411.

Miller, Daniel. 2012b. "Social Networking Sites.” In Digital Anthropology, by Heather Horst and Daniel Miller (eds.), 146-161. London: Bloomsbury.

Miller, David. 2005. "Immigration: The Case for Limits." In Contemporary Debates in Applied Ethics, by Andrew I. Cohen and Christopher Heath Wellman, 193-206. Oxford: Blackwell Publishing.

Newcomb, Alyssa. 2018. “A Timeline of Facebook's Privacy Issues—and Its Reponses.” NBC News. Published March 24. Accessed March 6, 2019. https://www.nbcnews.com/tech/socialmedia/timeline-facebook-s-privacy-issues-its-responses-n859651

Ong, Aiwha. 2003. Buddha is Hiding: Refugees, Citizens, the New America. Berkeley: University of California Press.

Oregon Department of Human Services. 2018. "Oregon's Refugee Arrival Population.” DHS. Accessed July 1, 2018. https://www.oregon.gov/DHS/ASSISTANCE/REFUGEE/Pages/data.aspx

Panagakos, Anastasia N., and Heather A. Horst. 2006. "Return to Cyberia: Technology and the Social Worlds of Transnational Migrants.” Global Networks 6(2): 109-24.

Pratt, Mary Louise. 1991. “Arts of the Contact Zone.” Profession. 33-40.

Price, Rob. 2018. "Russia Has Allegedly Been Spreading Far-Right Propaganda on Facebook to Try and Influence the US Midterms - and Here's How." Business Insider. Published October 27. Accessed March 6, 2019. https://www.businessinsider.com/right-wing-propaganda-allegedlyposted-facebook-russia-2018-10

Refugee Center Online. 2018a. "What is the RCO?" https://therefugeecenter.org/about-us/ourapproach

Refugee Center Online. 2018b. "Mission, Visions, and Values” https://therefugeecenter.org/about$\underline{\text { us/mission }}$ 
Refugee Center Online. 2018c. “Annual Report 2017.” https://therefugeecenter.org/about-us/2017annual-report/

Refugee Center Online. 2018d. “American Values.” https://therefugeecenter.org/resources/americanvalues/

Refugee Center Online. 2018e. "How to be polite in the USA and adjust to American culture." https://therefugeecenter.org/resources/how-to-adjust-to-american-culture/

Refugee Center Online. 2018f. “The Vision Fund.” https://therefugeecenter.org/vision-fund/

Roediger, David R. 1991. The Wages of Whiteness: Race and the Making of the American Working Class. London: Verso.

Roediger, David R. 2005. Working Toward Whiteness: How America's Immigrants Became White. The Strange Journey from Ellis Island to the Suburbs. Cambridge: New York City.

Rose, Nikolas and Pat O'Malley and Mariana Valverde. 2006. “Governmentality.” Annual Review of Law and Social Science. 2: 83-104.

Rosenberg, Matthew and Nicholas Confessore and Carole Cadwalladr. 2018. “

Sager, Alex. 2018. "Ethics and Migration Crises." In The Handbook of Migration Crises, edited by Cecilia Menjívar, Immanuel Ness, and Marie Ruiz. New York, NY: Oxford University Press.

Sassen, Saskia. 2016. “A Massive Loss of Habitat: New Drivers for Migration.” Sociology of Development 2(2): 204-233.

Sedrick H. 2017. "My Journey to America: The Best Thing That Has Happened to Me." The Refugee Center Online. https://therefugeecenter.org/voices/my-journey-to-america/

Shacknove, Andrew. 1985. "Who is a Refugee?" Ethics. 95(2): 274-284.

Sturgess, Peter, and Christine Phillips. 2010. "Google, Email, and Facebook: Internet Literacy to Improve the Health and Wellbeing of Newly Arrived Refugees and Migrants." Medical Student Journal of Australia, Australian National University 2(2). http://msja.anu.edu.au/archive/issue/03/internet-literacy-to-improve-the-health-and-wellbeing.php

Supreme Court of the United States. 2018. "TRUMP, PRESIDENT OF THE UNITED STATES, ET AL. v. HAWAII ET AL.: CERTIORARI TO THE UNITED STATES COURT OF APPEALS FOR THE NINTH CIRCUIT.” June 26. https://www.supremecourt.gov/opinions/17pdf/17965_h315.pdf

Uimonen, Paula. 2012. Digital Drama. Teaching and Learning Art and Media in Tanzania. New York: Routledge. 
United Nations. 2016. “A/HRC/32/L.20. The promotion, protection and enjoyment of human rights on the Internet." UN. Accessed September 27, 2018.

https://www.article19.org/data/files/Internet_Statement_Adopted.pdf

UNHCR. 1951. "Convention and Protocol Relating to the Status of Refugees." UNHCR. Accessed June 1, 2018. http://www.unhcr.org/en-us/3b66c2aa10

UNHCR. 1974. "OAU Convention: Governing the Specific Aspects of Refugee Problems in Africa." UNHCR. http://www.unhcr.org/en-us/about-us/background/45dc1a682/oau- conventiongoverning-specific-aspects-refugee-problems-africa-adopted.html

UNHCR. 2017. “The Rockefellers Have Always Believed in Welcoming Refugees.” UNHCR. June 29. http://www.unhcr.org/en-us/news/stories/2017/6/5955311f4/the-rockefellers-have-alwaysbelieved-in-welcoming-refugees.html

UNHCR. 2018. "Figures at a Glance." UNHCR. June 19. http://www.unhcr.org/en-us/figures-at-aglance.html

UNHCR. 2018b. https://www.unhcr.org/resettlement-in-the-united-states.html

US Citizenship and Immigration Services. 2019. “Obtaining Refugee Status.” USCIS. https://my.uscis.gov/exploremyoptions/obtain_refugee_status

Vora, Neha. 2013. Impossible Citizens: Dubai's Indian Diaspora. Durham and London: Duke University Press.

Wise, Raul Delgado. 2013. "The Migration and Labor Question Today: Imperialism, Unequal Development, and Forced Migration." Monthly Review 64(9): 25-38.

https://monthlyreview.org/2013/02/01/the-migration-and-labor-question-today-imperialismunequal-development-and-forced-migration/

White House 2017a. "Executive Order Protecting the Nation from Foreign Terrorist Entry into the United States." https://www.whitehouse.gov/presidential-actions/executive-order-protectingnation-foreign-terrorist-entry-united-states/

White House. 2017b. "Presidential Proclamation Enhancing Vetting Capabilities and Processes for Detecting Attempted Entry Into the United States by Terrorists or Other Public- Safety Threats."https://www.whitehouse.gov/presidential-actions/presidential-proclamation-enhancingvetting-capabilities-processes-detecting-attempted-entry-united-states-terrorists-public-safetythreats/

Wimmer, Andreas and Nina Glick Schiller. 2002. "Methodological Nationalism and Beyond: NationState Building, Migration, and the Social Sciences." Global Networks 2(4): 301-334. 
Zetter, Roger. 1991. "Labelling Refugees: Forming and Transforming a Bureaucratic Identity." Journal of Refugee Studies. 4(1): 39-62. 